UNIVERSITÉ DU QUÉBEC À CHICOUTIMI

\author{
MÉMOIRE PRÉSENTÉ À \\ L'UNIVERSITÉ DU QUÉBEC À CHICOUTIMI \\ COMME EXIGENCE PARTIELLE DE LA \\ MAÎTRISE EN ARTS PLASTIQUES OFFERTE À \\ L'UNIVERSITÉ DU QUÉBEC À CHICOUTIMI \\ EN VERTU D'UN PROTOCOLE D'ENTENTE \\ AVEC L'UNIVERSITÉ DU QUÉBEC À MONTRÉAL
}

par

Ronald Richard

CHAOSMOSE

ATELIER DU MONDE EN TRAVAIL implique EDN, BLL, NOE

(Programme d'un espace en travail /

Ode à Gaétane Morin)

JANVIER 1999 


\section{Bibliothèque}

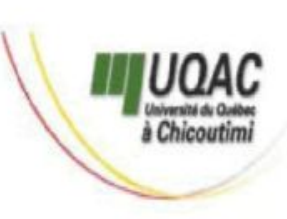

\section{Mise en garde/Advice}

Afin de rendre accessible au plus Motivated by a desire to make the grand nombre le résultat des results of its graduate students' travaux de recherche menés par ses research accessible to all, and in étudiants gradués et dans l'esprit des accordance with the rules règles qui régissent le dépôt et la governing the acceptation and diffusion des mémoires et thèses diffusion of dissertations and produits dans cette Institution, theses in this Institution, the I'Université du Québec à Université du Québec à Chicoutimi (UQAC) est fière de Chicoutimi (UQAC) is proud to rendre accessible une version make a complete version of this complète et gratuite de cette œuvre. work available at no cost to the reader.

L'auteur conserve néanmoins la The author retains ownership of the propriété du droit d'auteur qui copyright of this dissertation or protège ce mémoire ou cette thèse. thesis. Neither the dissertation or Ni le mémoire ou la thèse ni des thesis, nor substantial extracts from extraits substantiels de ceux-ci ne it, may be printed or otherwise peuvent être imprimés ou autrement reproduced without the author's reproduits sans son autorisation. permission. 


\section{TABULA ROSA/TABLE DES MATIÈRES/MATIÈRE GRISE}

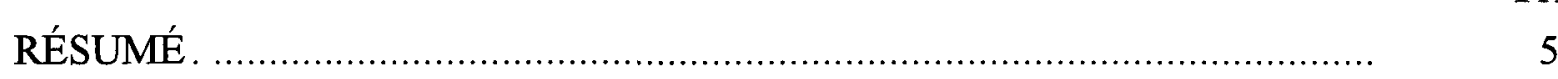

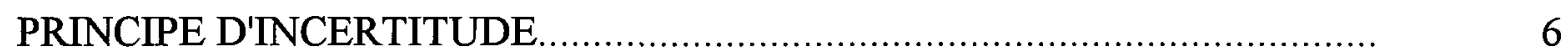

PROLOGUE: "RÉGLER LES COMPTES" .................................................... 7

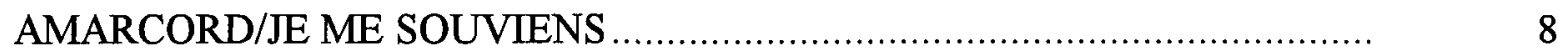

ARTITUDE: CONSTRUCTIVISME RADICAL ……..................................

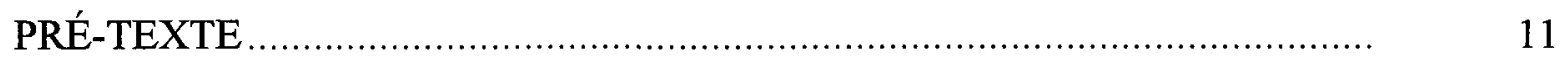

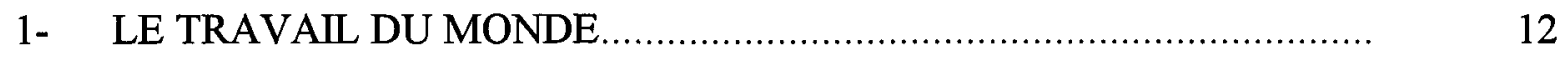

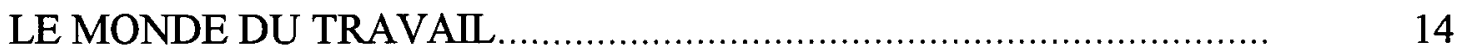

LE TRAVAIL DE L'ATELIER ……................................................

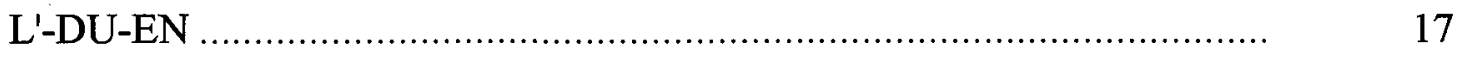

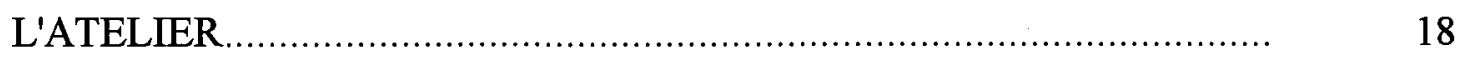

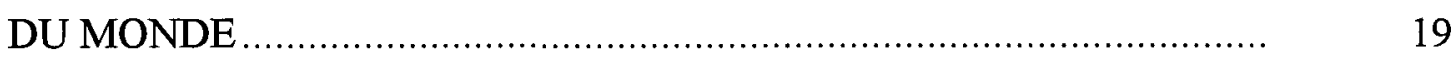

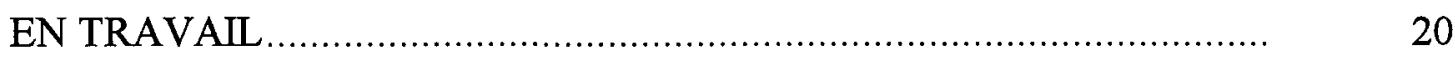

II- $\quad$ L'ATELIER DU MONDE EN TRAVAIL ……...................................... 21

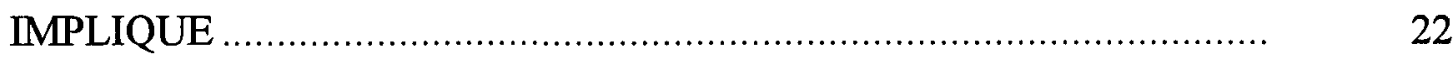

LE SORT DE L'OBJET/LA SORTIE DES OBJETS ……....................... 23

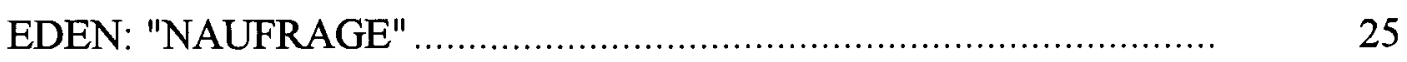

EDEN: "TERRE PLATE" ............................................................ 27

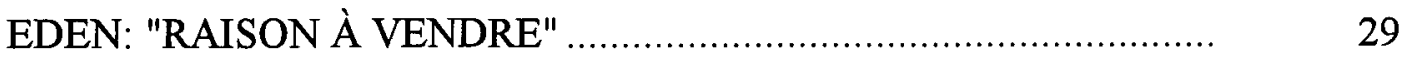

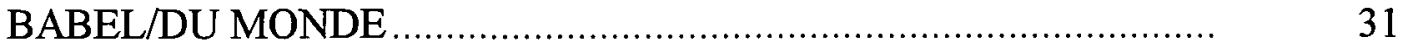

BABEL: "TRACTION" ..........................................................

BABEL: "HARRICANA" ........................................................... 
BABEL: "HOMMAGE À GUS PAQUET" ......................................

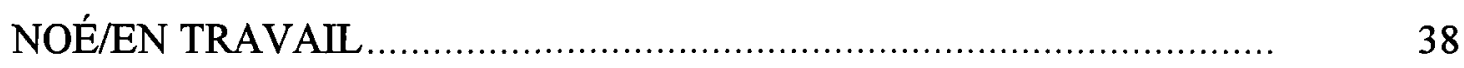

QUAND L'OBJET/RESSEMBLE/ À NOTRE REGARD:

"Hommage à Lissitsky" "Station" "Ancêtre mythique" ............................... 39

NOE: "ÉMERGENCE" ..............................................................

NOE: "CAPITAINE AUX LONGS DÉTOURS" .............................. 45

NOE: "TON MANOIR MON TROU NOIR" ..................................... 4

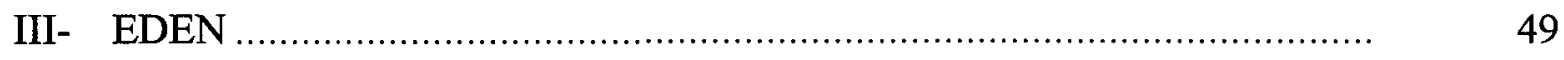

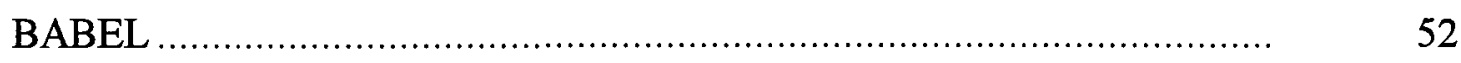

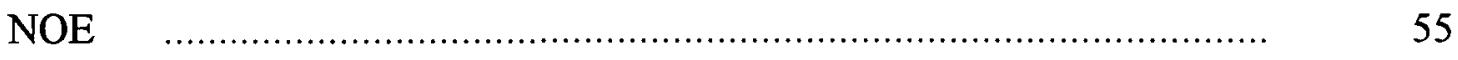

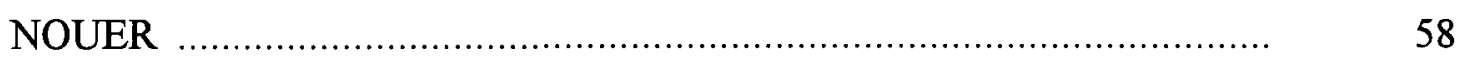

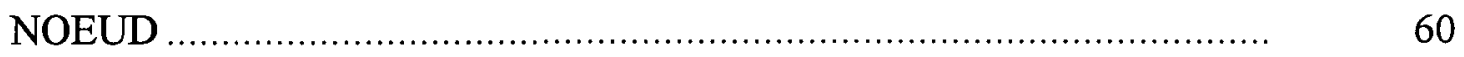

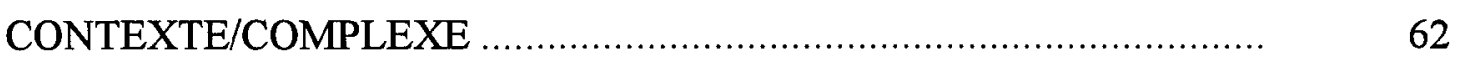

IV- EBN/ARTEFACTS DU PATRIMOINE MONDIAL ............................... 64

EBN/UN PLAISIR EN TROIS ESPACES ….........................................

EBN/UNE CHAÎNE D'ESPACES SURDIMENSIONNÉS ....................... 66

EBN/UN RÉCIT POLICÉ D'OBJETS FRACASSÉS ................................. 67

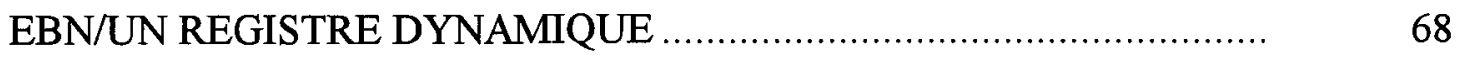

EBN/UN ESPACE INAUGURAL DU CONSTRUCTIVISME ................. 69

EBN/UN COLLECTIF CONTRE LA FATALITÉ ................................. 70

EBN/UNE STRUCTURE VERNACULAIRE ........................................ 71

EBN/UN DRÔLE DE RÔLE POUR UN CONSTRUCTEUR ................... 72

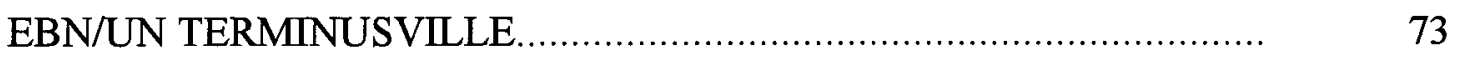

CHAOSMOSE: CONSTRUIRE DU RÉEL …........................................ 
CHAOSMOSE

ANNEXE:ATELIER DU MONDE EN TRAVAIL implique EDN, BLL, NOE 77

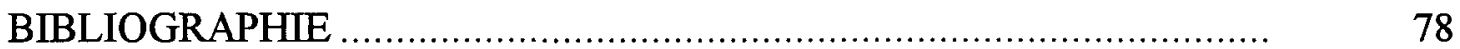




\section{RÉSUMÉ}

\section{CHAOSMOSE}

\section{ATELIER DU MONDE EN TRAVAIL implique EDN, BLL, NOE}

\section{Le passé peut-il servir le présent? Comment?}

Utiliser les figures archaïques d'Eden-Babel-Noé comprises comme réservoir mythique et technique (archéologie) pour développer l'espace du vernaculaire. Proposition réversible, formalisation programmatique d'un processus, énoncé d'un horizon, celui d'une réflexion phénoménologique qui permet de relever dans ces figures le caractère spécifique de la dynamique locale qui les anime. Une sympathie à l'égard des préoccupations de la physique contemporaine théories du chaos, des catastrophes et fractales, du moins ce qu'un fonctionnement par analogie nous permet de retenir, sert d'opérateurs formels. L'analyse des trois figures permet de dégager une conception de l'espace. Ce dernier, en échelle de complexité s'instaure par la découpe, s'amplifie par le pli, s'affirme, dense, par le noeud: rêverie topologique. Approche géométrique par surface, ligne, point. Un paradigme archéologique tend à enclore le travail: la réalité est stratifiée. L'esprit prélève, recase: la sculpture comme le moi sont considérés en couches, avec variance d'échelles. Au plan de la pratique, le paradigme holographique assure que l'information est diffuse dans la totalité de l'objet. À l'hypostase de la figure du créateur opposer l'assomption de trois monuments humains, contre la téléologie de "la croix ou l'enfer " substituer la contamination de l'espace du quotidien.

La communication déterminera alors si ces objets localisés dans la région mitoyenne de la sculpture et de l'architecture, le vernaculaire, appartiennent à l'espace de la modernité ou de la post-modernité et si l'on peut y déceler une perspective en continuité avec la tradition axonométrique, lui ajoutant césure, incrustation, rupture d'échelle. L'espace comme profondeur sans fin, et l'objet dont le bois est le matériau privilégié, sont compris comme rupture stochastique.

Chaosmose, mot valise processus de transformation. 


\section{PRINCIPE D'INCERTITUDE}

Lorsqu'on est animé par ce désir puissant d'exprimer une totalité, tout se passe comme s'il devenait handicapant de chercher à définir à la fois les particularités des mouvances d'un processus qui donnent sa raison d'être à un objet et de déterminer en même temps la localisation spécifique des parties de cet objet concret sculpture porté par ce processus non moins réel.

Retour post-moderne peut-être dans cette recherche décapante de la nature de la réalité qui fasse écho à l'embarrassant enjeu que questionne la physique théorique aux débuts de ce siècle. Tout indique alors que la détermination synchrone de l'état du mouvement et de la localisation des particules d'un système, ici atomique, ne saurait se faire qu'au prix de limitations réciproques. Comme si la tentative d'harmoniser la spécificité de l'objet et les particularités de son mouvement local se faisait par fluctuations des états du phénomène quelque part autour d'un état bien réel mais à valeur moyenne quasi statistique.

Par extension analogique, nous entendons Niels Bohr énoncer un concept de complémentarité qui impose une limitation réciproque à la détermination spécifique de ces deux variables.

Tout ça en grande partie parce qu'il existe pour moi, sculpteur, une matière primitive, le bois, dont le caractère non linéaire détermine des agrégats d'objets que mesure concrètement l'espace de l'atelier. Espace qui serait de caractère orthogonal à l'intérieur du gîte, espace qui pourrait s'expérimenter ondulatoire à l'extérieur du bâti. Espace tous deux conçus comme profondeur sans fin parce que divisible à l'infini.

Objet sculpture, conception granulaire discrète, discontinue qui masque irréversiblement des informations capitales concernant la structure locale du mouvement spécifique qui les anime.

Toujours par logique analogique appeler à la rescousse le principe d'indétermination énoncé par Heisenberg afin qu'il soit bien compris que dans le texte qui suit l'accent est mis sur le caractère global de ce qui caractérise le mouvement entendu comme processus dynamique que scandent et relancent nos objet. Ce mouvement n'étant pas plus nos sculptures que la carte n'est le paysage et notre installation... une équation. En avant donc! 


\section{PROLOGUE: "RÉGLER LES COMPTES"}

"Dans sa dimension minimale ce texte est compressé".

D'entrée de jeu, mais est-ce une entrée et en ce cas n'est-il pas risqué d'y jouer? Dire ainsi: "D'entrée, étant le mille et unième mot". Puisqu'il suit immédiatement une image et son lieu commun ou à tout le moins l'espace que lui attribue le parler populaire "L'image vaut mille mots". Mais lesquels, et surtout dans quel ordre et à quel rythme? Donc bien compter et régler les comptes...

Car enfin, le choix des mots référant aux éléments de l'objet et de l'image qu'on s'en fait, en utilisant les aller-retour "battus à plate couture" des sentiers de l'analogie pourrait aisément faire correspondre les substantifs lexicaux aux composants de la réalité de cet image. Ce tissage qui relie de façon "tricotée serrée" et l'objet imagé et sa transcription au langage relève de l'ordre descriptif. Par l'attribution de nominatifs, il énonce.

Que cette transcription descriptive, que cette cartographie reportée des contours de l'objet dans la série lexicale s'incorpore sans heurts peut faire à première vue étalage apparent de maitrise et bercer le lecteur par sa fluidité.

Mais si cette entrée de non-jeu ouvrait sur un objet en mouvement et que de plus ce mouvement n'avait rien de rassurant serait-ce vraiment utiliser avec sagesse et profondeur les procédures de la correspondance analogique que de lier celle-ci au rythme idéalisé d'une vie que l'on espère toujours voir couler comme un long fleuve tranquille?

Or c'est un fait, les objets ici, pris au retour de leur classique fuite par la perspective à l'infini, et les images qui nous les rapportent, ont une mémoire. Et il nous a semblé que la communication accompagnant l'oeuvre gagnait en fidélité et en clarté en épousant, par les procédés du langage, cette mémoire. Puisque la quotidienneté qui scande nos vies et ses objets en crise brise l'image lisse en miroir de ce roman-fleuve coulant des jours-fleuves.

Objets doublement éclatés donc, puisqu'ils sont d'une part issus d'usages vernaculaires mais échoués aux rivages de l'espace de l'art (de la sculpture) et d'autre part parce qu'ils se donnent à voir comme résidus du montage d'un ensemble en mouvement chaosmatique. 


\section{AMARCORD/JE ME SOUVIENS}

Ces objets, par leur mise en scène-et l'image en témoigne-, gardent cette double mémoire fracturée à la fois des usages du quotidien et de la dynamique singulière du mouvement qui les entraîne dans sa norme.

L'étincelance baroque produit un discours entre amertume et désir qu'étreint la hâte. Cette mise en forme fait percevoir le fond comme chaotique: excentrique au discours normatif mais centré sur l'objectif.

Mémoire dont nous avons tenté de transmettre la communication par notre utilisation du langage. En tissant et en incorporant un ton normatif au ton narratif et d'autre part en tressant aux substantifs réguliers des mots-valises et des expressions idiomatiques qui ressortent du langage populaire.

Et alors, tout comme la réalité en mouvement de nos objets sculptés nous apparaît stratifiée par les figures du chaos, des fractales et de la catastrophe, ainsi nous est-il apparu que la navigation à l'estime entre les registres du langage et de sa lexicologie étaient de nature plus appropriée pour traduire cette stratigraphie. (Noé figure emblématique de l'espace sculptant.)

Les figures régissant ces objets étant situées aux racines de l'origine de notre monde, tout comme ce bruit de fond à l'horizon du big-bang, ainsi de ces références aux racines, à la radicalité des termes utilisés.

Car il ne s'agit pas ici de se définir un but, d'assommer une vérité ou de témoigner d'une logique discursive qui révélerait une thèse statufiée mais d'offrir un texte visqueux et contaminé, porteur de la paralogie de nos objets pro-thèses en retour singulier d'un espace.

Se risquer à souhaiter qu'un paradigme holographique gouverne l'ensemble, c'est-à-dire qu'à chaque apport d'éclat de sens un mouvement progressif vers la mise au point de l'image d'une totalité se précise... sans jamais s'atteindre. 


\section{"ARTITUDE" CONSTRUCTIVISME RADICAL}

Ce discours à figure d'oxymoron part en flamme vers les lieux mythiques.

La figure d'origine entraine la construction. Est radical ce qui se situe aux racines des origines et la structure, logée au centre de la construction émerge, construction venant du latin struere, radical de radix, racine. Soit ce qui tient à l'essence des choses, ce qui vise à agir sur la cause profonde des effets qu'on veut modifier.

Une position existentielle et positive se déduit. Cette attitude souveraine par laquelle un sujet détermine l'espace de sa réalité porte un nom. C'est le constructivisme radical. Une position humaniste s'ébauche.

Le sujet invente sa réalité dans la pleine responsabilité et avec tolérance de l'autre (basé sur un relatif principe d'incertitude, - nous ne connaissons en effet que notre construction du réel). Attitude, tout à l'opposé du Verbe autoritaire qui s'énonce en "pleine connaissance de cause".

Ainsi, "le vrai est le même que le fait", (verum ipsum factum) dira Vico dès 1710. Un peu trop à l'écart de son temps. "L'intelligence ... organise le monde en s'organisant elle-même" annonce Piaget en 1937. Ernst von Glaserfeld en 1988 rajoute: "La connaissance est ce que nous appellerions aujourd'hui la conscience des opérations dont le résultat est notre monde empirique".

Ce n'est pas une reconduction perpétuelle du je. En plus de prolonger l'école artistique russe dans la sphère sociale, le constructivisme radical fonde une position d'ouverture à autrui. Le rapport entre les sujets (Eden - Babel - Noé) fonde l'identité (le symbole) et le collectif (le mythe) devient par la communauté reliée, le lieu du sacré. Pour qui veut saisir les conséquences, "un impératif esthétique: si tu veux voir, apprends à agir. L'impératif éthique sera: agis toujours de manière à augmenter le nombre des choix possibles", Heinz Von Foerster (Citations extraites de L'Invention de la Réalité de Paul Watzlawick et als.) Ainsi se sculpte dans le refus de la fatalité la base solide de l'auto-responsabilité revendiquée.

Construire c'est changer le monde et les rapports entre les choses. Ce qui implique une conception de l'espace qui se bâtit par l'objet. 
Raccommoder l'espace par tressage d'objets, un trou d'angoisse se comble, une plénitude intérieure apparaît lorsque s'accroît l'espace qui nous rassemble et nous ressemble. L'expérimentation se fait davantage par observation (lectures/photos/expos) et computation que par taponnages matériologiques. À la création par cuisine d'atelier se substitue une conception du monde comme atelier en travail que forge la dynamique chaosmose. Un objet parfois fait sens, comble un vide, réchauffe la planète, nous la rend plus habitable : architexture. Objet compris comme machine à processus, engin de sens. Ne pas voir en amont une cuisine d'artiste ni en aval un objet esthétique mais un objet fonctionnel de notre écart au sens du monde, une auto-construction.

Refus de la geste d'art comme reconduction repliant une création à l'origine et revendication pour l'humain du devoir d'occuper l'espace, tout l'espace. Fabrication d'objets travaillés par l'accouplement tordu du constructif et du surréel, ayant comme support théorique un paradigme archéologique dans lequel le moi et le réel se présentent comme stratifiés et un paradigme holographique par lequel l'information serait diffuse dans la totalité de l'objet. Un mouvement pulsant de concassage et compactage travaillerait notre modèle complexe du monde et gouvernerait notre représentation angoissante de ces séquences d'objets produits. L'objet exécute lidée.

Se mouvoir c'est changer. Proposition réversible qui torture la logique: stratification, viscosité, emboîtement autant de manifestations par lesquelles les éléments de ce qui bouge et reste semblable à lui-même distinguent ses parties de ce mouvement par variation d'attraction de forte à faible. Deux paradigmes en attracteurs étranges.

\section{Paradigme archéologique:}

Comme si la réalité se tissait par modes relationnels qui changent parfois radicalement de nature selon l'échelle d'observation (logique d'escabeau). "Quand ça change qu'est-ce qui n'est plus pareil?"

\section{Paradigme holographique:}

Tenter de choisir la géométrie la plus commode en fonction de la logique à construire.

L'information dans l'objet serait non séquentielle mais distribuée dans la totalité de son espace. Par ce procédé l'objet et son information acquiert une forme d'immunité aux détériorations radicales. "De ce qui casse, qu'est-ce qui résiste?" 


\section{PRÉ-TEXTE}

Le 4 juin 1988 est décédé mon père d'une thrombose après 34 ans et 10 jours de travail à titre d'instructeur en météo. En plus d'un legs à la Caisse Populaire, patronyme oblige, sur la commode à côté du lit, une lettre à mon intention jamais postée et que je reproduis "telle que telle:"

Anjou, 3 juin 1988

Ronald Richard

C.P. 69

St-Philibert

GOM 1 XO

Salutations:

Il est difficile de vivre, à preuve à plus ou moins long terme on en meurt tous. J'aimerais que tu réfléchisses à ceci, on en reparlera.

\section{Chaosmose}

L'Atelier du Monde en Travail implique EDN, BLL, NOE

À bientôt,

Ton père, Roméo

Lecteur quotidien du journal Le Devoir, il n'avait ni bible, ni bibliothèque; (occasionnellement allait-il à l'église par convenance). Seul le caractère subit de cette mort m'a souligné l'importance de ce message à première vue bizarre, abscons, hermétique.

EDN, BLL, NOE: une énigme, une construction, un naufrage.

"Tombé du ciel",

Devant moi se dresse un rideau de sens à dévoiler.

Ce qui suit tente de déployer cette aventure en une longue explication réflexive, toutes voiles larguées. Et la sculpture: son espace peut-il habiter la forme d'une proposition? 


\section{I- LE TRAVAIL DU MONDE}

Invictis Victi victuri

Aux invaincus, les vaincus qui vaincront.

EDN, BBL, NOE, trois naufrages?...

Une énigme!...

Eden, - Babel, - Noé "Magiciens de la terre, nous sommes les gardiens de ces figures, nous les réfléchissons." "Ces sculptures représentent la construction de notre raison, le rêve de notre maison." "Ici au centre la porte ouvre sur le sensible et à côté, dans la surface courbe du mur qui résiste, trois fenêtres percent le chaos..."

Comme constantes, trois figures résumant ces expériences. Et si en elles étaient scellées des caractéristiques fondamentales de l'espace occidental? Pourrait-on y découvrir un processus, une façon de produire des sculptures?

Il s'agit d'analyser trois régimes de dynamique et voir ce que peut générer leur rapport d'implication. Impliquer c'est-à-dire si...donc, ça...

Récit de la découverte d'une formule et de la recherche d'un plaisir. Le ternaire exprimant un ordre intellectuel dynamique, résolument non résolu, régime du processus, de son action spécifique et de la transformation conséquente de l'objet qu'il a travaillé. Ternaire, unité complexe du mouvement.

Fondamentalement, la motivation naît de la recherche d'un modèle de fécondité. Contemporain des recherches génétiques visant à dresser la carte du génome humain, aux alentours par analogie de la biologie, de la logique du vivant, dans la lignée des systèmes qui s'auto-organisent.

Comment l'étendue de la nappe symbolique pourra-t-elle clarifier le parti pris, la gravité, le poids sémantique de ces trois figures appréhendées? (Et les objets voudraient s'en faire l'écho).

Il faut remonter en amont, au point de convergence de ces dynamiques et trouver une interrogation pertinente à ce point d'intersection. Point situé en un lieu d'avant la théorie et la pratique, point qui ne nous est pas donné mais décrété par choix volontaire. Temporairement isolé ce point 
et les figures suspendues d'EDN, de BLL et de NOE comme estomaquées, les objets en deviennent d'autant fragilisés. Cette fragilité mettra-t-elle en évidence ce qui leur donne poids, ce qui les constitue réels. Objet devenu support à une dynamique, mouvement de prologue, argument de remontée: comprendre l'amont, l'origine de la source comme un point de convergence que l'on espère rationnel.

Objet contrasté, où le fragile se tricote au solide; l'énigmatique au réaliste; et l'hétéroclite au lieu commun: l'importance du choix du matériau prime l'imposture matériologique.

Choix volontariste de privilégier des matériaux et figures empruntés à l'usage et à la mythologie quotidienne dont la singularité est d'être construit sur la précarité d'un point situé à l'intersection de deux régimes de dynamiques. Ainsi, entre le catalogue du magasin et sa chambre à coucher, tenter de coincer en série un carnaval de meubles mutants et délinquants. Et travailler ce point comme lieu d'intervention sur la fuite de linfini. Et ce, par la représentation postmoderne entendue comme émergence du sujet local et singulier en tant que récit dans la singularité du processus de l'objet.

Le chaos, les fractales, la catastrophose émergent du construit.

\section{CARTOGRAPHIE}

$\begin{array}{llllll}\begin{array}{l}\text { Logique disjonctive } \\ \text { de moi/à toi et d'eux/ } \\ \text { à nous... }\end{array} & \begin{array}{l}\text { Fonction } \\ \text { commémo- } \\ \text { rative }\end{array} & \text { Découpe } & \begin{array}{l}\text { EDN Surface } \\ \text { Jaune } \\ \text { /vert }\end{array} & \begin{array}{l}\text { Infiniment grand Chaosmose } \\ \text { Profondeur fatale Chaos }\end{array} \\ \begin{array}{l}\text { Logique implicative } \\ \text { du jeu de je, à moi } \\ \text { vers soi... }\end{array} & \begin{array}{l}\text { Fonction } \\ \text { décorative }\end{array} & \text { Pli } & \begin{array}{l}\text { BLL Ligne } \\ \text { Rouge }\end{array} & \begin{array}{l}\text { Infiniment petit Chaosmose } \\ \text { Direction fatale Osmose }\end{array} \\ \begin{array}{l}\text { Logique intégrative } \\ \text { de je à toi, à nous à } \\ \text { eux... }\end{array} & \begin{array}{l}\text { Fonction } \\ \text { monumen- } \\ \text { tale }\end{array} & \text { Noeud } & \text { NOE Point } & \begin{array}{l}\text { Infiniment com- Chaosmose } \\ \text { plexe } \\ \text { Dimension fatale }\end{array}\end{array}$




\section{LE MONDE DU TRAVAIL}

$\mathrm{Au}$ roman des origines répond la métaphysique du présent: ancrée dans l'arkhè (Edgar Morin), l'image s'active ici/maintenant. Ainsi dit-on un instantané...

Voici quelque chose comme un raisonnement stratifié, logique d'escabeau, échelle d'enseignement. Le tout sous forme de litanie:

"Pédagogie: la lutte, les classes (T.V. années 55);

la lutte des classes $(60 / 65)$;

la lutte, ça casse $(65 / 75)$;

la lutte? on se case! (75/85);

la lutte, on se casse (85/95)".

Résumé éthique et méphitique des 40 glorieuses années de consommation... Notre façon de relier les choses longtemps a été agonique. Elle a consisté à détruire l'une en validant l'autre: relier, religere. Réfrigérer? Religion qui s'inaugure par un exil et se prolonge par la croix. Comme si l'homme craignait, en quelque lieu de lui-même, d'être trop de ce monde!

En continuant, la crainte horrible de tout réduire, tout écraser m'habite: "Une rage qui crée un mirage": $\quad$ JE BÂTIS

\section{TU HABITES}

\section{IL PROFITE}

Chercher à établir des rapports significatifs entre trois artefacts antiques échappés de la répétition érosive des habitudes qu'impose le rituel de la survie au quotidien, c'est tourner le dos temporaire ment aux conditions matérielles de légitimation de cette entreprise logée à l'enseigne de la boutique de l'art devenue parfois magasin général. Travail/Télévision: horizons non soudés de la quotidienneté chaotique. Un réel élastique, transparent s'expérimente, permis par l'osmose électronique. Mondialisé, le processus conjugue non sans heurts le chaosmatique. Comme le peuple porte le gouvernement, dans le système de l'art c'est toute la tribu peut-être qui porte la mode, il n'y a donc aucune singularité ni dans la recherche de nouvelles formes ou de nouveaux sens. Comme "l'eau va au moulin" c'est de l'espace du monde qu'il faut donner à la sculpture. 


\section{LE TRAVAIL DE L'ATELIER}

"Magiciens de la terre, nous sommes les gardiens de ces figures, nous les réfléchissons".

"Buter sur cet objet puisqu'il n'y a de buts que non atteints".

Nous sommes dépositaires d'une tradition et ces figures hantent notre raison. Pour que nos sculptures réfléchissent ces raisons hantées, nous les voulons porteuses de temps sensible. À l'alignement de nos maisons closes, coquilles de survie et standardisées par la publicité nous voulons ouvrir ces constructions telle une vaste opération porte ouverte dans les champs d'oeuvres, le long des routes de nos paysages, seuils critiques du nécessaire refus de la fatalité économiste, et devenues autant de fenêtres qui en percent le chaos.

Ce qui suit est la tentative d'inventer une réalité compressée qui me rassemble, soit synchrone à la complexité locale. L'espace de cette réalité est tangent à l'espace social actuel; s'entend par là qu'il n'en fait pas l'économie sans chercher à le heurter de plein fouet. Il cherche à traverser la sphère institutionnelle de l'art en refusant de se limiter à ses techno-critères programmés et prétend ouvrir des pistes. Oeuvres ouvertes dans le paysage, manifestement il ne s'agit pas seulement d'ajouter le labeur de nos sculptures à nos champs labourés (culture/agri-culture). Mieux que des formes inédites, c'est une conception de l'espace qu'il faut apporter à l'objet-sculpture!

Compactage/concassage, l'esprit se regarde fonctionner et agit d'un mouvement identique sur les objets, les casse et les ramène, les rumine et les respire.

Il y a dès lors urgence de faire suivre par la sculpture du sujet, la construction de l'objet. De chercher à mettre l'accent réellement sur le rapport dynamique plus que sur les termes de ce rapport, sur la fluidité qui circule sans tomber dans le virtuel. Accepter ainsi le risque d'un objet secoué par sa rencontre avec le chaos, fractalement divisé, catastrophé. Et se torturer pour lui conserver solidité.

L'objectif est d'illustrer dans un échantillon la thèse proposée de la complexité. Il s'agit donc ici de préciser et illustrer une question et — travail logique oblige — les objets aussi sont soumis à la question (travail/torture). 
Produit d'un espace compris comme profondeur sans fin, sans solution de continuité, il y a fluidité entre théorie et pratique qui opèrent en échelons: l'écrit comprend de l'esquisse (plan/projet) et du texte concret (précis et condensé) tandis que l'objet conçu en esquisse comprend du croquis et du matériau brut.

Sans taire cette sorte de désir de conduire le constructivisme jusque dans la sphère du chaotique, là où ça tourbillonne. Ainsi de quelque chose comme du Brancusi tordu... Pouvoir de contrôler son tourbillon singulier: "...maestra, maîtrise du maelström intérieur."

Contrat d'art construit, entendu comme vecteur du patenteux/bricoleur tendu vers l'orthogonal constructiviste mais tordu (oblique/spirale). Bricoler introduit l'oblique et le provisoire là où l'adroite construction s'érige en principes qui tendent à la permanence. Construction linéraire, bricolage biaisé... La patente qui allie le bricolage à la construction sauve celle-ci du fondamentalisme orthogonal.

Ardent désir d'une forme solide mais qui précontrainte par l'oblique, le tordu et le compressé devient composite, compliquée, complexe, tout en résistant néanmoins au fracas.

Recherche d'une méthode de pensée. De penser l'espace et d'aussi le peser. De poser dans cet espace un objet, de peser dans cet espace et de le dépenser aux ultimes marges de l'effritement.

Une sculpture est un objet revenu d'une traversée de l'espace, un art utile, un art outil pour traverser et s'emparer de l'espace de l'utile. Les moyens utilisés sont pauvres... Mais que signifient richesse ou pauvreté ici: le coût d'achat ou l'économie de la crise? La dépense ou la compression des sens?

"Gardien de la mémoire;

Regardeur de la fatalité;

Guide du refus": puisqu'il n'y a de buts que non atteints. 


\section{L'-DU-EN}

Comment départager par l'expérience la substance de l'accident? La vérité du réel c'est le fait, c'est-à-dire ce qui résiste. Art et math fonctionnent sur le vraisemblable et ont comme première réalité commune de répondre à une définition. Privilégier alors pour des raisons tactiles, l'adhérence à une idée à l'idée d'adhésion! Dans la mouvance des éléments du processus, croire que la viscosité, si l'on pouvait lui donner charge d'émotion, possède une valeur de rémission. Lorsque "ça coule de source", certaines associations freinent la fluidité, cette gravité visqueuse piège parfois avec intensité le sens.

Ici le processus d'osmose est inversé, nous avons une réponse et en cherchons la question. Dans cette énigme d'EDN, BBL, NOÉ investir dans l'expérience de fabrication comme lieu avantagé, propice à départager les parcours féconds. C'est toujours l'ensemble du processus qui importe. Une partie du paysage abandonne le marcheur, une partie l'accompagne.

D'où cette tentative de renverser la perspective. C'est-à-dire de signifier la théorie par l'objet - en suivant la logique de la pratique - et la forme par le discours (logique d'escabeau), au lieu d'assigner la théorie au discours et la forme dans l'objet. Tout en soignant le contexte de vision.

Nous en arrivons alors à un processus de construction d'objets qui,nous l'espérons, en arrivera peut être à bâtir une oeuvre. La connaissance change avec l'expérience de l'objet, cette expérience de savoir est pouvoir. Ainsi donc de cette suite d'objets faits mains, manoeuvre, oeuvre manifeste.

Comme base de connaissances actuelles, un réseau. Et par stratégie, dans une logique de réseaux s'impose la nécessité de connaître les paradigmes de l'autre. Non plus "Dieu" ou les "Sciences" mais des infiltrations, des cohabitations avec l'inconnaissance. L'anxiété est calmée par l'attention centrée sur les processus. On ne compartimente plus: une forme ici répond à une autre là-bas. Ici est-ce encore une partie de la maison raisonnée ou suis-je déjà dans la construction phantasmée?

EDN = Comment le passé active le présent?

BLL = Jusqu'où peut-on sculpter trop loin?

NOE $=$ Quel espace type donner à nos objets? 


\section{L'ATELIER}

"Ces sculptures représentent la construction de notre raison, le rêve de notre maison".

ATELIER: un lieu qui rassemble des gens d'une classe déterminée, des ouvriers et l'étymologie définit l'activité par l'accident: estelle = éclats. Objet-sculpture donc comme la concrétude discrète d'un état actualisé de la pensée.

Poser d'emblée l'origine et la singularité constante du mouvement caractéristique de litération occidentale. Leitmotiv et ritournelle, EDN, BLL, NOÉ n'ont d'autre but que cela; tout à l'opposé de la reconduction d'une figure d'autorité, elles cherchent - chaosmose - à se fracasser dans une série d'objets. Ce mouvement se loge bien moins dans l'oscillation ample qui départage le site du nomade du gîte du sédentaire. S'il ne s'y cadre pas c'est parce qu'avant toute chose ce mouvement, fractalisant vers l'infini la figure inaugurale d'EDN, c'est le cadre qu'il instaure: région, cité, nation hier, maintenant colonial, international et demain spatial. À défaut d'affirmer dans l'instant sa singularité locale on encourt toujours le risque, étranger à soi-même, de se retrouver le "régionaliste" d'une quelconque métropole du pouvoir. Mouvement qui ne se joue pas dans les pistes du manque et de l'avoir mais plutôt s'érige dans les classes du pouvoir et du savoir.

Lieu commun:... à la question de la réalité de la nature, poser la question de la nature de la réalité et, citoyen du monde, en sculpteur répondre à la conquête de l'espace par l'exploration spatiale.

Dans l'installation comme dans le multimédia, l'utilisateur construit son scénario. La sculpture d'environnement, - socle, cadre et support - se déplaçant littéralement dans le réel du monde, privilégie la circulation, forme renversée de la composition. Abri de Noé, forme inversée de la nef...

La réalité est que l'on circule dans la vie et que l'on s'installe dans la mort. Dès lors, lieu de catastrophe, l'objet se stresse, processus construit du front du refus de la fatalité. Ainsi en est-il donc de la théâtralité de linstallation qui construit la représentation. Y voir le passage de la reproduction du réel à sa mise en production. Ce qui précède n'ayant d'autre fin que de clarifier la question: "Comment réintroduire la dimension épique d'un sujet dans l'architecture?" 


\title{
DU MONDE
}

\author{
"La mesure de l'écart entre la réalité du monde et mon sens de l'harmonie est de \\ $0.1415296 \ldots "$
}

Ce qui est fait doit être mesuré par un espace mondain usuel, qui ressort de la pratique quotidienne. S'il s'agissait d'architecture, on dirait vernaculaire. Pour y parvenir, l'aller-retour constant dans les quatre axes du sens s'avère indiqué: sensibilité, signification, orientation, perception. Tout comme je n'existe que mesuré, ma sculpture me rassemble et n'existe que dans un espace concret hors duquel "point de salut " ou "fuite à l'infini " dans la chute du dogme perspectif à point unique. Cette sculpture habite un lieu, elle ne prétend surtout pas le transformer. Il est à souhaiter qu'elle ne s'y dilue pas, ne se délie pas; puisse-t-elle résister à ce vide et s'y substituer...

Ne pas oublier également que les propositions du chaos déterministe sont aussi, en sciences humaines, des équations de turbulence. Ces équations véhiculent à la fois des effets et des affects! Elles ne "modèrent pas leur transport"; alchimie, elles transportent du matériau brut à l'athanor de l'imaginaire. Elles charrient même parfois des "états d'âme".

Miroir inversé de l'aphorisme énoncé par Maurice Denis, une sculpture n'est pas qu'un assemblage de pleins et de vides (un fromage...) en un certain espace rassemblé. Objet au sein d'un monde d'objets, matière dans un continuum matériel, il est idéaliste de rêver d'un certain âge d'or du matériau, d'une matière hypostasiée comme un dieu. Dans notre monde, tout matériau est à double articulation, comme le langage, et le papier sera lourd ou léger selon quil sera blanc ou publicitaire. Téléologie de l'hypostase, jamais il ne sera innocent.

Construction d'objets, tentative de domestication de ce monde dans lequel nul n'a demandé à vivre et dont la fatalité nous exclut.

Plate. Plate forme spatiale de ce sujet lancé dans le vide. Construction: processus mental. Premier mouvement par lequel s'installe et survient une pensée dans l'opacité de l'objet. Tentative moins d'une assomption que d'une assomptuosité de l'objet: le prendre avec soi, l'assumer certes jusqu'en ses origines et ce parce qu'en lui toutes les strates du sens se dépensent somptueusement. Ainsi donc, tissage et travail, science et réversibilité: accepter que les équations transportent des valences et des valeurs, tissent des rapports et des reports et travaillent à mener à bon port. 


\section{EN TRAVAIL}

"L'esprit humain doit premièrement construire les formes indépendemment avant que nous puissions les trouver dans les choses.

A. Einstein, in: Leonardo, vol. 26 \#1192, p. 327.

Comme "Travailler au corps" de la sculpture - Travail, Torture... échange de bons procédés. Le travail compris comme tissage de sens. Toute forme s'installe dans un sol mental, avant de s'installer dans un sous-sol matériel. Théorie/pratique: rapports de forces de gravité.

Travailler - 1080 - latin populaire, torturer avec le trepalium - 3 pieux. Modifier pour soumettre à une action suivie pour donner forme.

Torturer - 1190 - bas latin tortura - 12's: injustice fin 12's - Tort - 13's Torsion.

Souffrance physique infligée pour faire avouer (à la sculpture) ce qu'elle refuse de révéler. Avouer que je parle de ce vide théorique, travail in-situ de tissage pour donner corps à la théorie, la suite des connaissances, les livrer, délivrer ce qui se produit, livrer cette vaccination, ce qui marche, livrer la marchandise et parce que les mots vibrent se dire que le livreur arrive en chantant!

S'essayer à produire sens, lieu du paradis retrouvé. Nommer ce qui se passe, se tricote. En découdre avec soi-même "à plates coutures", torsion oblige, surtout ne pas rester sur son "quant $\grave{a}$ soi".

EN TRAVAIL: en promesse de développement, en contraction, en gestation (gestalt). En voie de s'auto-produire, donc définitivement quelque chose ici fait relief.

EN TORTURE: vient de Trepalium, trois pieux de bois instrument de torture. Un effort se fait. Ainsi, le bois travaille et cet effort se produit dans le continuum du matériau. Des fentes ouvrent des écarts: produit d'intensité projetée dans une direction donnée. Travail manuel avant qu'intellectuel! En travail, par extension, "la pratique fonde la théorie".

Commander aux mots une dynamique en harmonie avec celle éprouvée par l'expérience avec l'objet. 


\section{II- L'ATELIER DU MONDE EN TRAVAIL}

Pour mémoire: le processus coule, circule et circuite. Mémoire souvenance en travail. Non pas tel un mémoire, sorte d'écrit exposé cherchant à scinder, à diviser, à couper entre objet et sujet par exemple. Mémoire au sein d'un processus en réseau dont le mémoire à l'emporte-pièce, en découpe dira-t-on, profile les faits. Mémoire, libellé d'un factum. Mémoire qui dépasse l'exposé et partie prenante de ce qui se tresse dans le processus, de ce qui le tend et le stresse.

Comment clarifier que ce qui précède a pour but de témoigner de l'ampleur de cet espace archaïque, de ces figures à fonctionnement archétypal dont l'étendue de la nappe symbolique fait des vagues, invente son aventure réelle serrant dans son périple et de manière évidente ses contours limites. C'est dans les méandres langagiers que zigzague sa course, dans la littéralité métonymique de l'allitération. Dans le bondissement des résonances, dans les couches de raisonnements stratifiés (mettre fin à sa faim en avalant le menu et de travers pour faire "bonne mesure").

Par renversement de perspective, déclarer que l'autonomie de l'oeuvre, c'est son anomie et que l'audience est un facteur fabricant décisif de l'objet.

Perspective: l'objet est produit en vue de quelqu'un. Renversement de perspective: il n'y a pas de vide! Dans cette optique, nous et nos sculpture habitons dans un mouvement continu. Là s'affirme comme autorité le rapport d'échelle en tant que perception en "zoom in/zoom out". Les objets se hiérarchisent: "La main fermée sur la maquette, corps à corps avec le modèle au pied du monument, s'y dépassant même..."

Sentiment oppressant du complexe et de l'agonique.

Pourquoi la complexité? Parce que c'est moins sur la composition de l'eau que sur le flot de la rivière, sur le processus dynamique que porte l'attention. Ainsi dit en analogie avec les sciences physiques et pourquoi "agonique"? Lié à la mort, cet objet nous épuise et ce qui tisse notre vie s'y retrouve et s'échange dans le processus d'auto-production de cet objet. Post-moderne, souligne quelque chose comme émergent - immanent - transitant, en un mot l'accent mis sur le supervenant.

"Atelier du monde en travail "précise la dynamique du site, le momentum investi. 


\section{IMPLIQUE}

Énoncé replié autour de sa dynamique, il s'agit d'une proposition d'implication. Logés à l'enseigne d'un paradigme spatial, les termes se compressent, donnant apparence de force immuable à la proposition. L'explication déroule dans l'espace des objets le texte des éléments plissés pour leur redonner totalité. Au fatum d'origine répond le factum de l'instant. Agir casse la fatalité. Car dans la linéarité apparente du texte trois dynamiques se casent. Linéaire comme lieu de l'incertitude statistique; non-linéaire comme lieu de la certitude chaotique. Entre elles, un espace discontinu où se précipitent et condensent les sculptures : espace comme surface infinie ou tension superficielle? Rapports topologiques? À la création par le vide du Verbe répond l'invention par le trop plein de l'objet. Double radicalité de l'espace d'origine et des principes fondamentaux... Proposition née de litinérance, de longues marches écartées, hors des rituels quotidiens, projet avoué de rallier une continuité, de trouver des constantes à notre tradition culturelle, de se relier à ce mouvement dynamique.

Plie, replie et déplie. Rassemble encore incisif et lapidaire en noeud. Participant du plan de travail de la découpe et gardant la ligne mince du pli. Ni entièrement noeud, ni totalement neutre car en son centre le noeud neutralise bien des contraintes. "D'entre ciel et terre", comme on dit se défilant entre "chien et loup", chute le soleil point flottant. Fait et défait l'horizon, toujours en risque de passer à la catastrophe: paquet de noeud, nerfs sous tension. Éclats, brille, éclate... À l'image même du Tao qui s'ancre dans le vide et se présente en question, ici, par les opérations de découpe, de pli et de noeud, telle une coupure d'origine dans le rapport traditionnel qui relie l'hypostase à la téléologie, EBN, forme compressée d'Eden, Babel, Noé, en s'y substituant construit un noeud, comme réelle sculpture en trois espaces.

Ainsi d'un énoncé de base qui se décline et dont les termes se définissent comme une mise au point focale au fur et à mesure de la résonance réflexive. L'explication entendue ici comme déroulement, dépliage, révèle le sens non pas par un objet intime caché au fond de ceux-ci, il n'y en a pas. Dans l'orientation de ses plis (marges/masques, emprises/empreintes) elle détermine un mouvement, un processus. Opposée à la dispersion, la compression devient facteur de murs, d'abris, de percées, d'avenues et découpes en échelles variables "logique d'escabeau" construites en inclusions et mises en abimes. Opérations construites de localisations/délocalisations, objets immigrants, migrants, émigrants. Post-perspectivisme? 


\section{LE SORT DE L'OBJET/LA SORTIE DES OBJETS}

RITOURNELLE: L'objet de l'objet est ici le sujet:

Ce sujet n'est pas l'objet

La mort n'est pas la mort de l'objet

La mort est l'objet Fatal

Contre la fatalité, ces sujets...

\section{TRADITIONNEL/CLASSIQUE/RADICAL:}

Art de tradition au sens de tradere, échanger, tisser, tramer (remettre/transmettre) emmêlant aux graffiti des tavernes les pictogrammes des cavernes, opposant la signalétique, aux tics en série et l'effet du monumental et de la mise à distance, au désordre mental.

Objet classique qui mérite d'être imité, qui peut faire école et se réconcilie avec la copie - et la photocopie - comme forme d'apprentissage.

Projet radical: qui tente de produire un objet fonctionnel solide intègre et puisse se décadrer de l'autoréférentiel, du fragment et du virtuel.

Le retour de l'oeuvre sur elle-même donne à l'objet une dimension théorique, d'où la pertinence d'analyser le système de l'oeuvre à travers les procédés.

Selon les stratégies d'approche utilisées, dans ce processus d'auto-réflexivité, c'est l'oeuvre qui se donne pour objectif de se réfléchir elle-même comme résultat "tricoté serré" de matériau passionnel et de matériau historique. Le social, c'est le lieu d'appartenance. Le faire, c'est la construction et l'objet s'y découpe par effet de contraste et contour. La matérialisation du concept, voilà le corps de la sculpture.

Recherche d'un objet nodal en dérive. La géométrie comme symbole de raison, rien de plus. Penser l'art devient théorie des singularités et l'analyse la tentative de révéler ce qui est en travail, ce qui se tord dans l'objet.

RITOURNELLE: "Au début était l'objet" (les traces font preuves)

"L'objet fit l'homme" (de la préhistoire à la renaissance)

"L'homme fait l'humain" (de la renaissance au siècle des Lumière)

"L'humain fait l'objet" (révolution industrielle, intelligence artificielle) 


\section{EDEN/L'ATELIER}

\section{Stratigraphie de l'objet:}

Dessin/Esquisse:

Croquis/Atelier:

Maquette:

Modèle:

Monument:

Architexture:
Phase proto-archaïque

Période archaïque

Logique d'échelle

Viscosité (fait des petits)

Contamination (fait le vide)

Tricoté serré au vernaculaire

Maquette, monument, modèle dimensionnent l'objet. Là où le modèle mesure les rapports de qualité, d'entre maquette à monument, c'est la quantité volumétrique qui se scande. Objet devenu solide par structure tripolaire de construction par collage, assemblage, installation.

Ici c'est l'espace qui est en travail. Objet/espace: en tant qu'objet immobilier, la distinction entre les éléments, les constituants et les composants internes d'une part et les rapports entre l'emplacement, les dépendances, les annexes et le gros oeuvre au niveau externe d'autre part, permettraient de schématiser les unités fonctionnelles de l'ouvrage global.

Dans cette itération formelle, les significations s'enchaînent, se "cathénarisent" par leur rapport de proximité et, tel un processus d'osmose, solidifient l'objet. L'objet porte son chaos comme un danseur africain porte son masque. Que l'objet se mette en point aveugle et en abîme de lui-même, c'est ici que les idées s'agglutinent, apparence trompeuse de linéarité, "théoria" littérale... En réalité, par effet de contiguïté, l'opacité commande d'aller voir "quossé qui limone là-dedans".

Objet construit de façon à ce que la sculpture habite le spectateur, le plan est fait avec de multiples entrées. Les éléments ont un sens, la totalité de l'ensemble un autre. Une mise en boîte des sens. 


\section{EDN: "NAUFRAGE"}

L'objet naufrage - Voyons, dans l'espace de ce montage tiré au grand air, l'espace démonté des rêves et dans ce qui fait relief, le relevé de la délivrance d'une tragédie à tiroir...

Les choses n'étant jamais tout à fait faites à notre image, elles débordent parfois de ce qu'elles semblent être. Ainsi, de cette tentative de construire des objets beaux et pathétiques, déchirés par leur passage coïncé entre l'architecture et la sculpture, d'entre l'immeuble et le mobile, du consommable utilitaire au déchet rejeté: rebute, rebuts, rebuts... Rébus

Naufrage, ce bureau porte son potentiel tout comme dans l'espace complexe du rêve plusieurs états différenciés cohabitent. 
Naufrage

Granby 95 


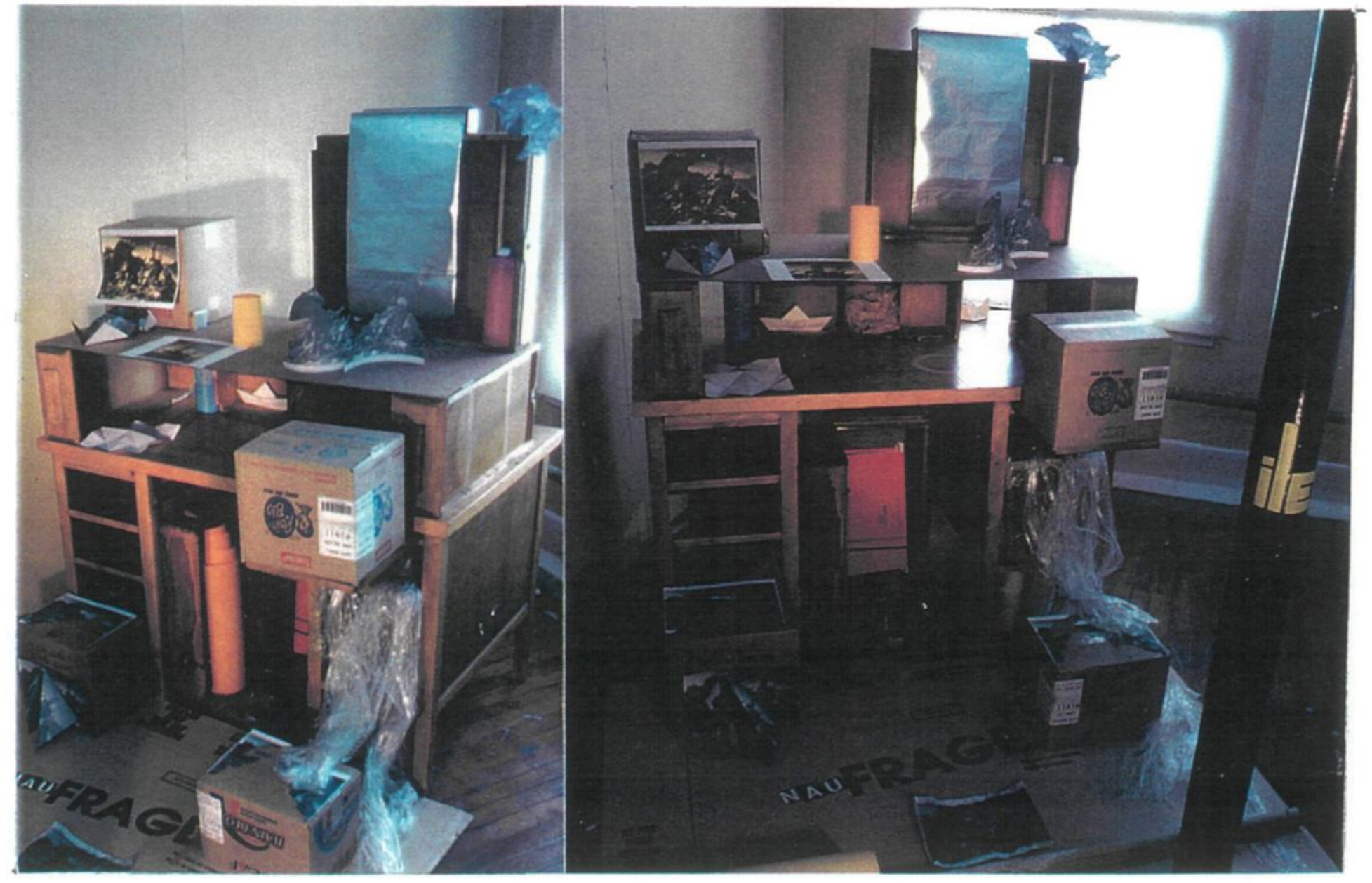




\section{EDN: "TERRE PLATE"}

Parfois certaines parties imaginaires de l'objet se délivrent dans le réel: deux états dans un même objet (chiasme/chaos).

Tenter de réaliser le front d'onde, de fixer ce brouillard à catastrophe par une accumulation d'objets que rendent flous les interpénétrations de sens. Souligner le réalisme des objets par matériaux usuels archivant leurs traces de production: papiers imprimés, matrices connues, formes géométriques. Les "bibittes" font figure d'apparitions.

Objet - Tabula rasa - Tableau des matériaux - Table des matières - Matière grise.

Comment cartographier le chaos dans un monde orthogonal?

Où est la solidité du réel? Mêler, et que gagne la matière grise... 
Observatoire (Terre Plate II)

Granby 95 


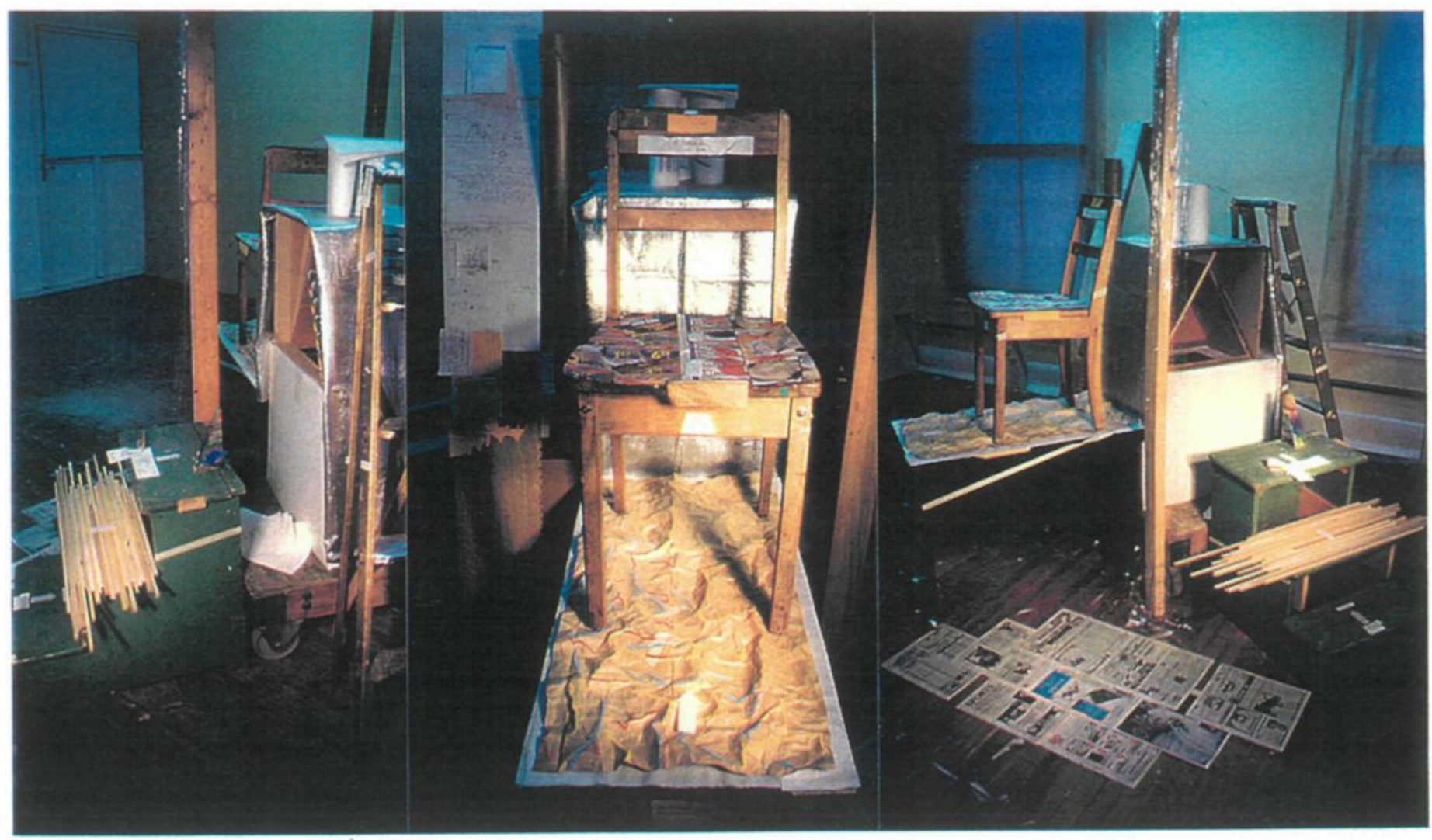




\section{EDN: "RAISON À VENDRE"}

Constructions vivantes avec leur mémoire, leur processus, leur histoire (leurs manques et leurs restes et leurs rebuts). Reconstruire une finitude stochastique en utilisant tout le matériau d'origine sans rejets aseptisés. Maison porteuse de sa mémoire.

La part des choses, archéologie, interprétative liée à l'apport des choses, leur charge affective.

Objet: "À matériau banal, traitement imprévu". Si l'on pouvait définir une chose par tout ce qu'elle n'est pas, le contour de sa réalité se découperait là où elle résiste au banal. (Banalité de la boîte de carton orthogonale, par exemple...). Des figures se déclinent, déclinent partiellement leur identité et circulent dans le noyau de l'objet. Tentative de délier et relier par l'utilisation de l'arabesque/contour/silhouette/découpage.

Certaines formes s'agglomèrent, d'autant d'autres tombent. Construire c'est en premier lieu répartir l'espace des phases. EDN, BLL, NOE fonctionnant comme attracteurs étranges métaphoriques. Construire aussi ces attracteurs par la structure complexe des figures.

Pliage, contraction de l'espace des phases.

Stratification, fractale à l'infini dans l'espace des phases. 
Raison à vendre

Granby 96 


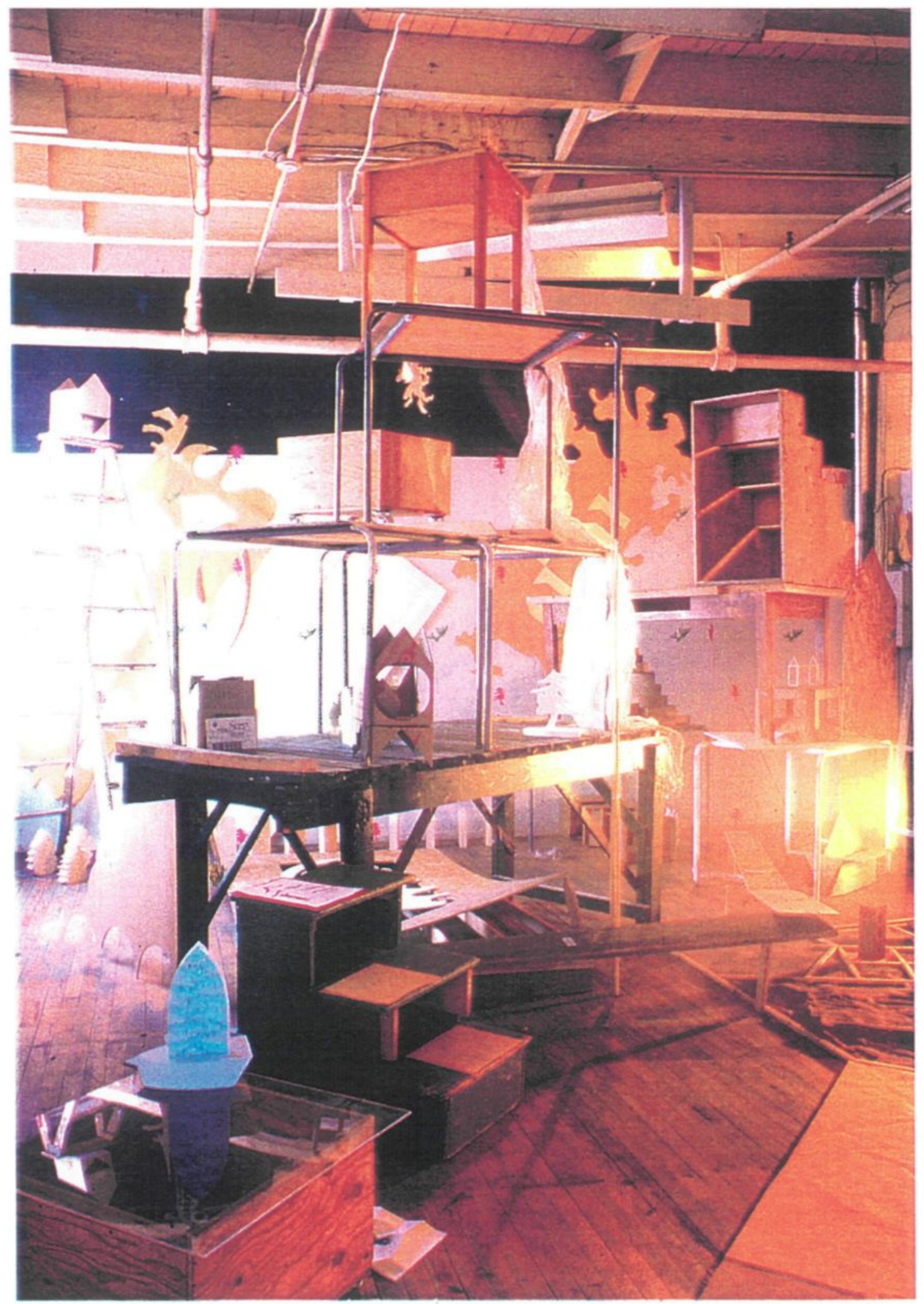




\section{BABEL/DU MONDE}

Oeuvre carrefour tendu entre théorie, pratique. Trois réalisations qui s'installent aux confins de la sculpture installative et de l'espace public.

Il devient urgent pour grandir que l'objet né de nos mains ne s'y mesure pas, faute de quoi, ne mesurant que les éléments à l'échelle humaine, l'humain serait mesure de tout. Et alors..."se sentir déplacé" est une invitation au déplacement dans le réel.

L'étalement de l'objet porte l'état actuel de la sensibilité vers les conditions initiales par le refus de l'hypostase en tant que fatalité et par l'émergence de trois figures constructives. Cette sensibilité singulière est celle de la rage de vivre par le collectif.

EBN, formulation contractée d'Eden, de Babel et de Noé. Du verbe éternel, par l'éternité de l'instant: le Big-Bang de la Fête. La sculpture s'étale, EBN s'y véhicule et les sens détalent: foire collective, attracteur étrange. EBN courbe la surface de cet espace.

"Nappe", "histoire","collectif", espace en expansion comme condition initiale de la sculpture. Objet carrefour qui structure le mouvement, la circulation, comme une argumentation agie, le déroulement d'une proposition.

Il y a utilisation de l'allégorie dans ces productions, dans l'effet sériel. Le motif fait signe; il positionne et stabilise l'objet dans la chaîne des signifiants.

En ce qui concerne l'avènement du sens à l'instant privilégié où l'objet fait sens, la route du sens devient pour l'objet sa façon d'exister, cette route coïncide avec le prolongement de la chose.

Et alors l'oeuvre sans motif infantilise le spectateur en se présentant comme gribouillis (ou bouillie analogue au "bruit" en communication). Les éléments perçus sans rapports combinatoires "ne font pas rap...". L'écart augmente la signification, ce monde dans lequel nous vivons ne devenant qu'une longue vérification d'attentes (les piliers ne bougent pas!) et de déplacements improvisés. 


\section{BABEL: "TRACTION"}

Sculpture construite et qui chemine comme du bricolage périphérique.

Une forme ruse transformée en lieu d'échange, hiérarchise et distribue le sens; éventuellement elle fait le vide. Avec un centre solide et contaminant qui agglomère. Une "forme-lieu", construite par la spirale, non pas une "forme-dieu". Une forme qui rassemble et permet les échanges. Des matériaux idéologisés et réalistes mettant en acte un rapport intérieur/extérieur, se livrant et se délivrant, entraînés par la dérive d'une thématique engageante, sculpture d'installation d'éléments existants, mobiliers modifiés par des préoccupations picturales...

Parlons d'installation, disons sculpture et mentionnons que chacune fonctionne sur un mode binaire: faisant office de support structural, en droit fil du rapport socle/objet chacune est contenue, son port est déterminé par une pièce de mobilier, (meuble/immeuble: évaluation gagnepain...) meuble d'usage quotidien. Du bois chargé de bois. Du bois organisé qui se prend en main et s'organise à son tour...pour faire un tour.

Toutes marches dehors, un escabeau ouvre la marche, crête hérissée de bardeaux de cèdre, bâton de commandeur ancré sur la tablette du haut: résultat ironique du solennel, de la procession. Errance ou itinérance? Avec une allure un peu guindée, chaque élément du cortège possède au moins un axe vertical de symétrie, ce qui renforce la zoomorphie.

Banc, chaise, table, planche à repasser, étagère, escabeau, support échafaud, chevalet: comme constituants de la matière support, déclinaison à partir du bâton, de la règle qui découpe. Comme une longue théorie de base(s), de points d'ancrage, une énumération comme un alphabet très ancien.

Effet d'auto-réflexivité, ici se conjuguent: porter, apporter, supporter, comporter, déporter, transporter. Comme les six composants de cet ensemble qui constituent linstallation comme une molécule complexe...

Parade, théorie ouverte sur le ganoué "gang-way" du collectif! 
Traction

St-Honoré 91 


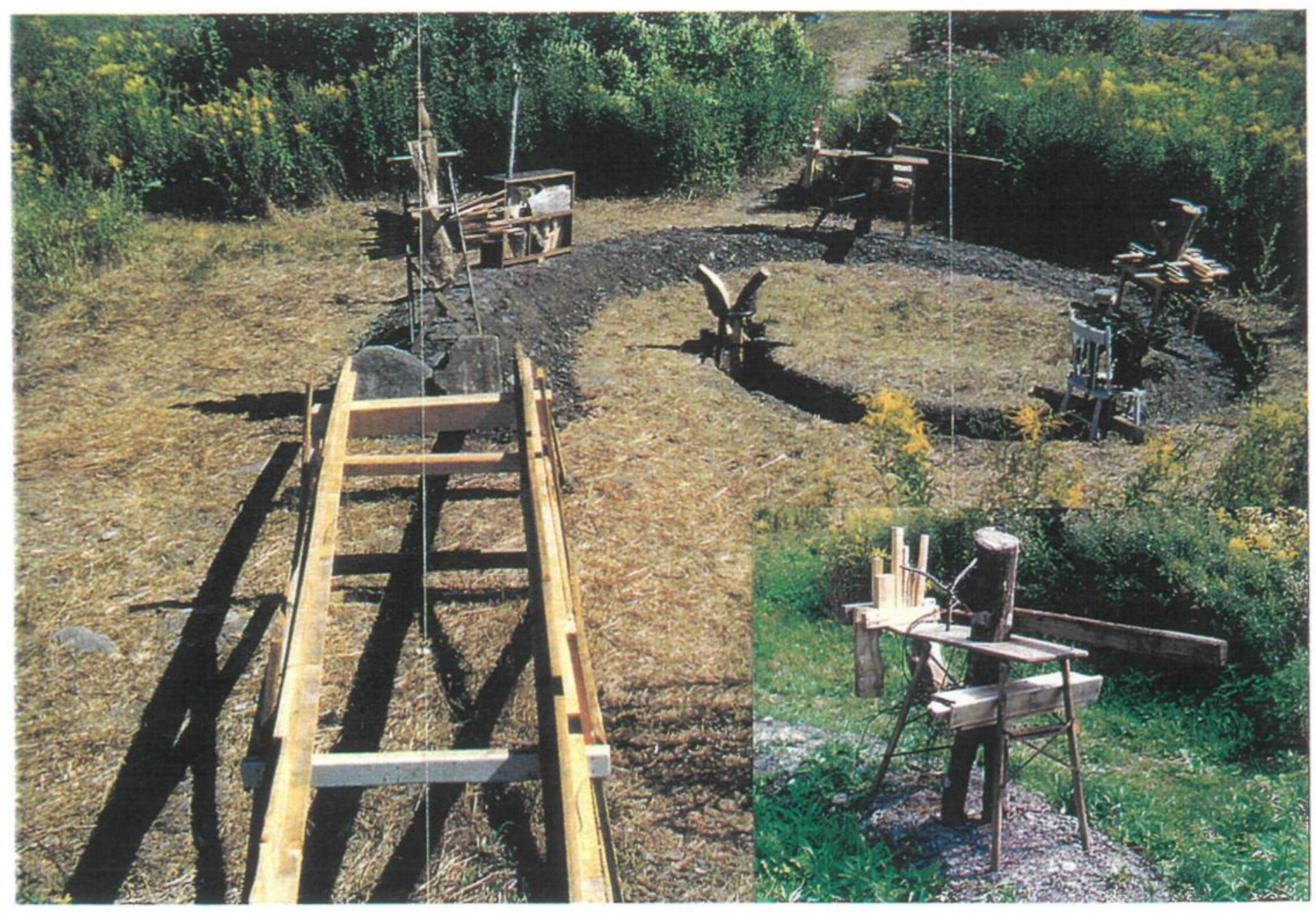




\section{BABEL: HARRICANA}

"Harricana! Très liée, grande et humoristique".

350e anniversaire de Montréal: commémorer par un cercle de stèles l'assemblée des grands hommes locaux, par exemple Marx Fortin.

Réversible, vue de l'extérieur, la même série devient enfilade de facades de maisons, un fort. $\mathrm{Au}$ centre, un trou: dans l'axe Sud/Nord, la tranchée du guerrier devenant, dans l'autre axe la tombe des nations autochtones écrasées par le mouvement Est/Ouest de l'irruption "civilisatrice" de l'Occident (roulant "tombeau ouvert, évidemment!").

La porte de sortie, un autoportrait de l'absence, donc celle d'une silhouette évidée: le paysage lointain la comble. Il s'agit d'un homme des bois, la tête dans les nuages.

Harricana signifie "longue route" en algonquin, poursuit une thématique qui se veut sensible aux minoritaires. La matrice générale par cercles concentriques se donne à lire comme stratigraphie. L'accumulation des éléments éclatés mais liés, compactés par la matrice formelle solidifie l'objet. La figure de stèle/maison utilise des procédés de construction issus en droit fil de l'architecture vernaculaire.

L'usage analogique de ce que nous avons compris de la théorie du chaos a permis de bâtir deux régimes dynamiques d'où émerge "l'homme des bois". Signal d'une silhouette rouge embusquée dans un bosquet. Ami, ennemi?

L'apparition d'une série de formes échevelées, le plan très simple, c'est-à-dire une série de cercles concentriques, comme des pelures d'oignons, comme autant de strates archéologiques dont les sens s'ajoutent tout en tournant à des régimes différents. Au centre un trou: dans l'axe est/ouest l'axe de la conquête civilisatrice porteuse de l'extermination des amérindiens: c'est une fosse. Comme l'archéologue vandalise son objet au nom de la culture, comme il doit le détruire couche par couche pour en saisir le sens, ce trou au centre est pour un corps mort, c'est une tombe: six stèles d'ailleurs la regardent. 
Harricana

St-Honoré 92 


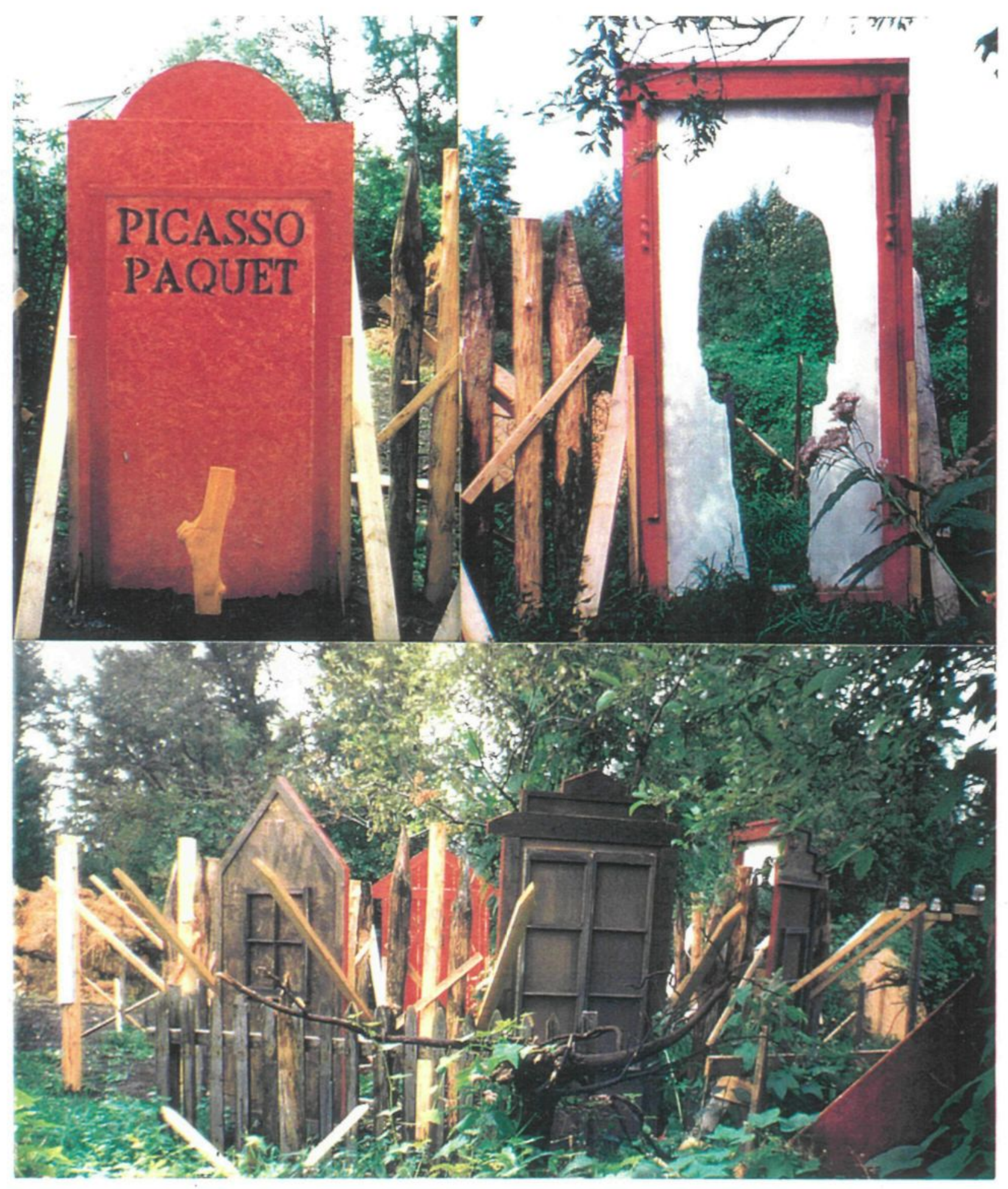




\section{BABEL: HOMMAGE À GUS PAQUET}

Donner corps aux choses en donnant sens aux limites. Découper le sens dans l'uniformité du monde: préserver le centre en rendant signifiante la découpe, par la forme, la silhouette, l'arabesque. Un centre solide et solidaire. Tout ça littéralement.

Situer les centres de ces compositions. Ainsi le contour de linstallation se veut-il une forme signifiante. De même qu'à la découpe fracturée et ligne de lecture répond une surface de protection, de même à l'éblouissement du sens répond un point aveugle.

Ne pas circonscrire les éléments par une figure totalisante qui reconduise l'hypostase, au contraire au pied du mur, souligner une émergence. "Donnez-moi une hache/je bâtirai un monde..."

Tenter de donner un climat d'expansion illimité. L'objet devenu un carrefour de pistes, que le spectateur le traverse et poursuive sa route.

S'essayer à obtenir des formes d'échange, "visages à deux faces", multifaces pour fonctionner en interface et produire un réseau où la circulation physique du spectateur produit le sens.

Projet d'étalonner les éléments comme une traversée, comme si l'on jetait un pont. Stratification des moyens et procédés, unification par l'arabesque dans le paysage: marquer cette ligne frontière entre deux mondes.

René Thom dira qu'on a, avec la notion de "bord" un exemple où, du point de vue formel, une partie détermine le tout. Une dynamique est un espace et une application de cet espace en luimême. Il y a donc des points fixes, des invariants, des rapports contractés:

Passage : mort/vie

Porte : esprit/matière

Ailleurs : trivial/poétique

Symbolique : constructivisme/surréalisme. Et la découpe souligne alors l'absence, l'immatériel, la vulnérabilité, la mort... 
Hommage à Gus Paquet Notre-Dame des Pins 97 


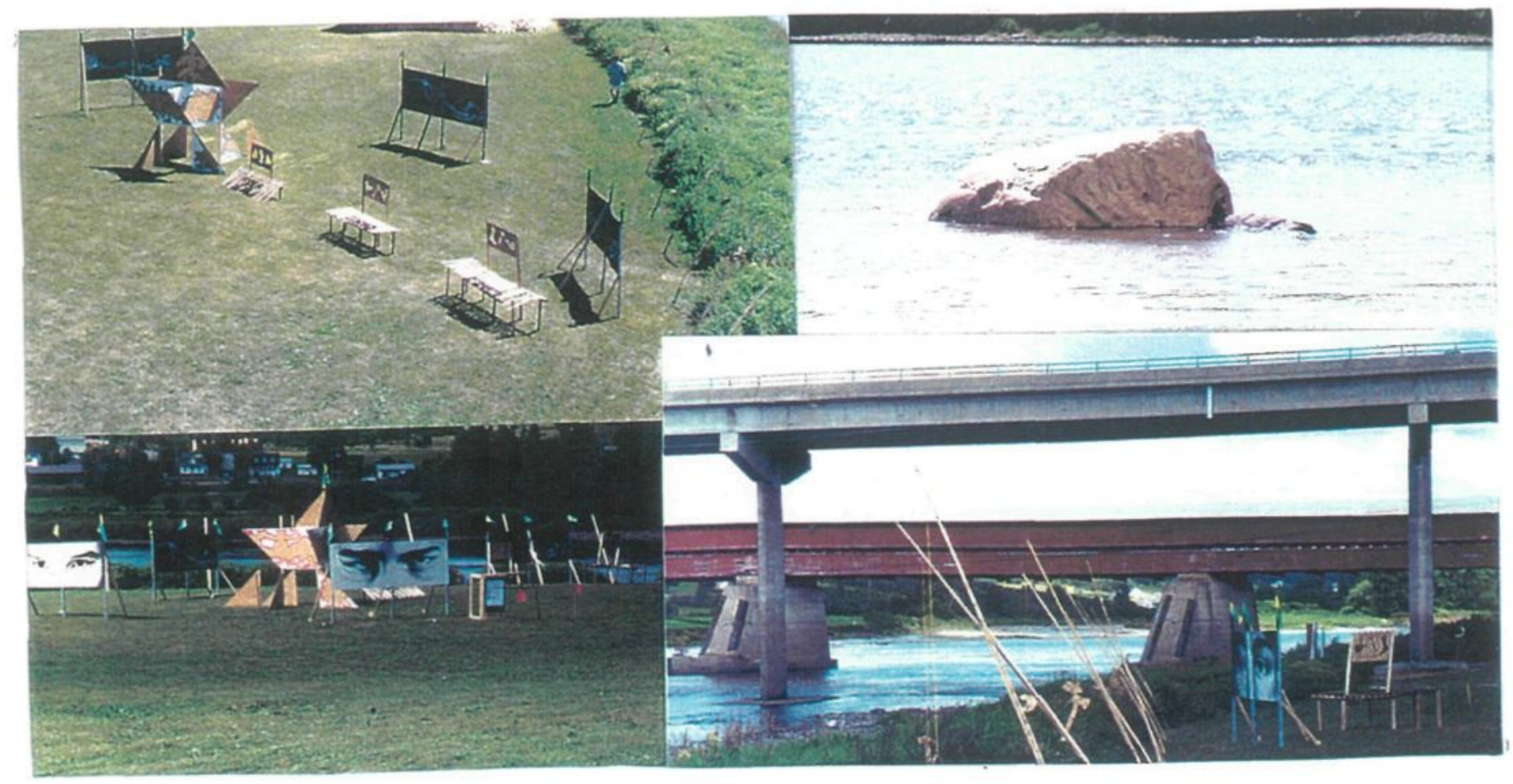




\section{NOÉ/EN TRAVAIL}

L'événement tend à compresser l'architecture dans le monumental. Donnant assise à l'objet, il l'amplifie du lien privilégié de la fonction commémorative.

Selon l'expression courante, "souligner l'événement". Façon de le sur ligner en fait. Pathétique recherche de l'écart, tentation de l'inédit tout en sachant que dans une société de communication, par sa répétition, sa redondance, un signe perd son relief et se banalise. Avenues mercantiles de la marque, de la griffe, la signalétique prend le relais des tics en série.

En faisant le vide autour de lui, l'effet prophylactique du monumental aurait-il la prétention de guérir du désordre mental? Ombres tutélaires des monuments, haltes privilégiées du flot touristique.

Par les textures des matériaux travailler les turbulences plutôt que jouer des formes et des couleurs. Travailler dans le paysage, le marquer par ancrages, et non pas travailler sur le paysage.

Tout ça à l'image d'une pierre jetée à l'eau, l'eau s'y révèle par ses rides, lignes de front, front du refus, catastrophe. Front d'onde.

Paradoxe du simplifié et du complexe...

Rapports parfois complexes pour des objets désirés simples.

Érigés dans le quotidien, que leur faut-il à ces objets pour qu'ils ne fassent l'économie de la crise? 


\section{QUAND L'OBJET/RESSEMBLE/À NOTRE REGARD}

\section{"HOMMAGE À LISSITSKY"}

Foule/Furie

Objet signalitique. Refus de la fatalité par laquelle se présente l'idéologie dominante. Conception par strates superposées de l'objet marque d'une sympathie pour l'archéologie.

Photo tressée, drapeau dressé, toile stressée.

\section{"ANCÊTRE MYTHIQUE!}

Proposition à l'échelle monumentale: au sol, une forme de maison se retrouve miniature, au sommet d'un escabeau et quasi soutenant le plafond. L'ensemble possédant un vague appel visuel de totems Haïda. Littéralement "échafauder un argument vernaculaire..."

\section{"STATION"}

Échelles compressées: dolmen miniature, chaise monumentale. Racines à l'air, "monde à l'envers". L'or de Beauce, l'art ça paye. Sculpture griffée et bilingue: "NUL, NUE, CUE, CUL...". Là où le socle devient spectacle. "Les baguettes en l'air". 
Hommage à Lissitsky Québec 1979 


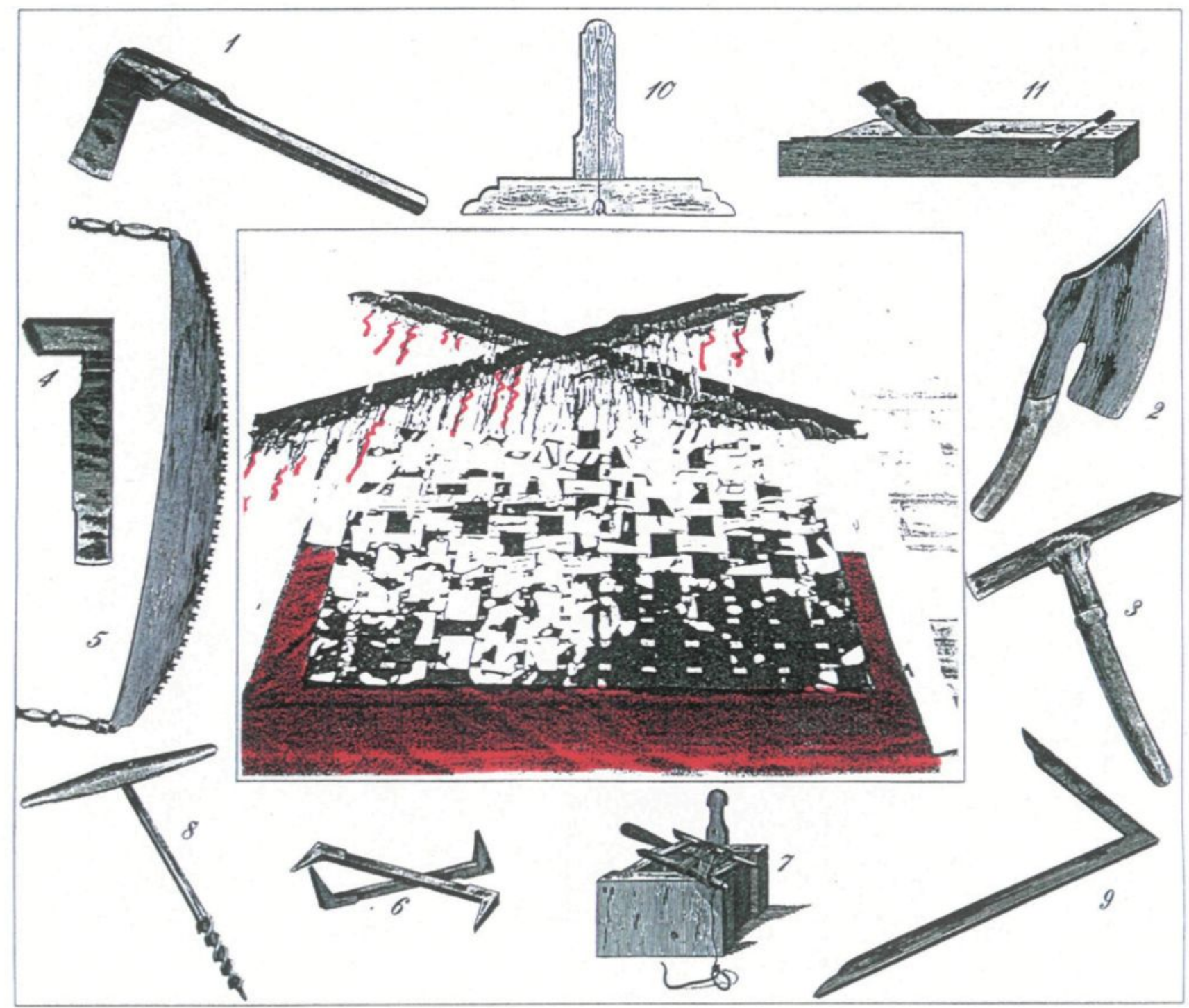


C.I.G.I.T./C.E.G.E.P. (Ancêtre Mythique II) Vallée Jonction 98 


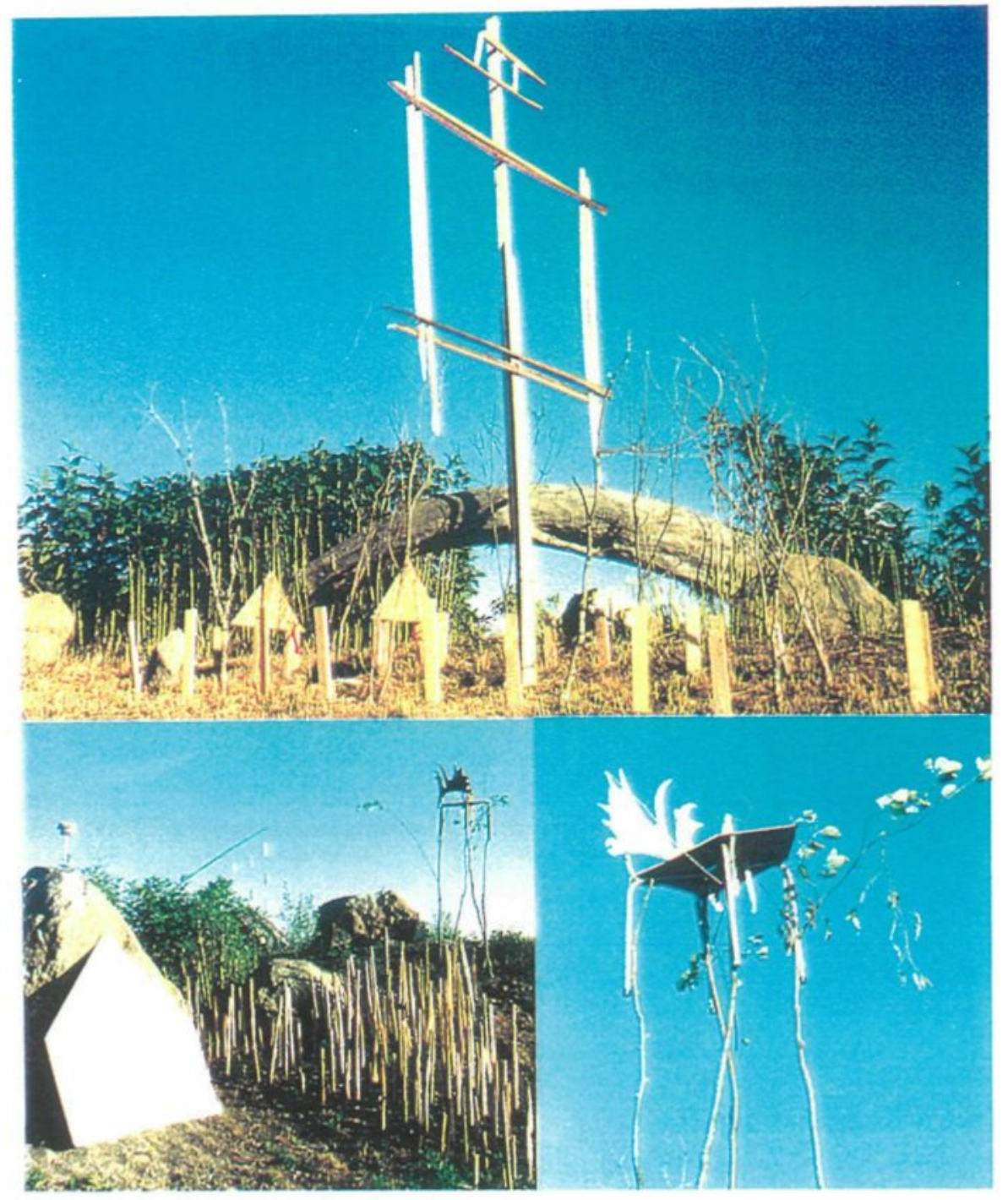


Station

St-Hilaire de Dorset 91 


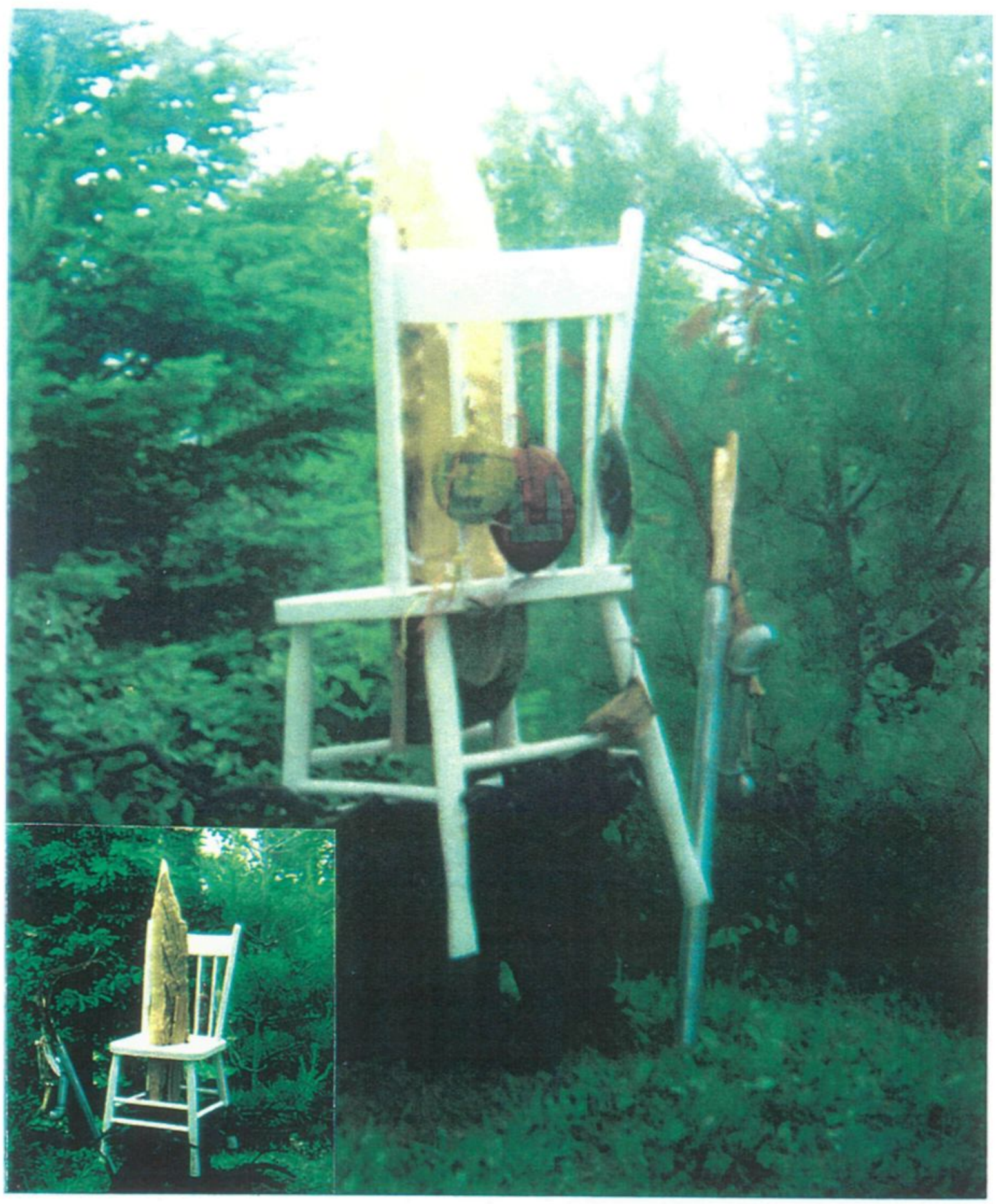




\section{NOÉ: "ÉMERGENCE"}

Tentation de synthétiser l'émotion ou de créer une émotion de synthèse en facilitant l'appréhension sensible de la structure: construire et construire les émotions c'est prendre pouvoir sur les choses.

L'humour du livre: "Rien ne prévaudra contre elles". Maison, raison fluide...

Une sculpture compactée, comme une vision, un éclat qui se compresse. Structure installée comme marque de passage, dans un lieu de passage, sous le soleil quotidien vernaculaire.

"Cartographier le chaos dans un lieu fluide...?" 
Émergence

St-Joseph 95 


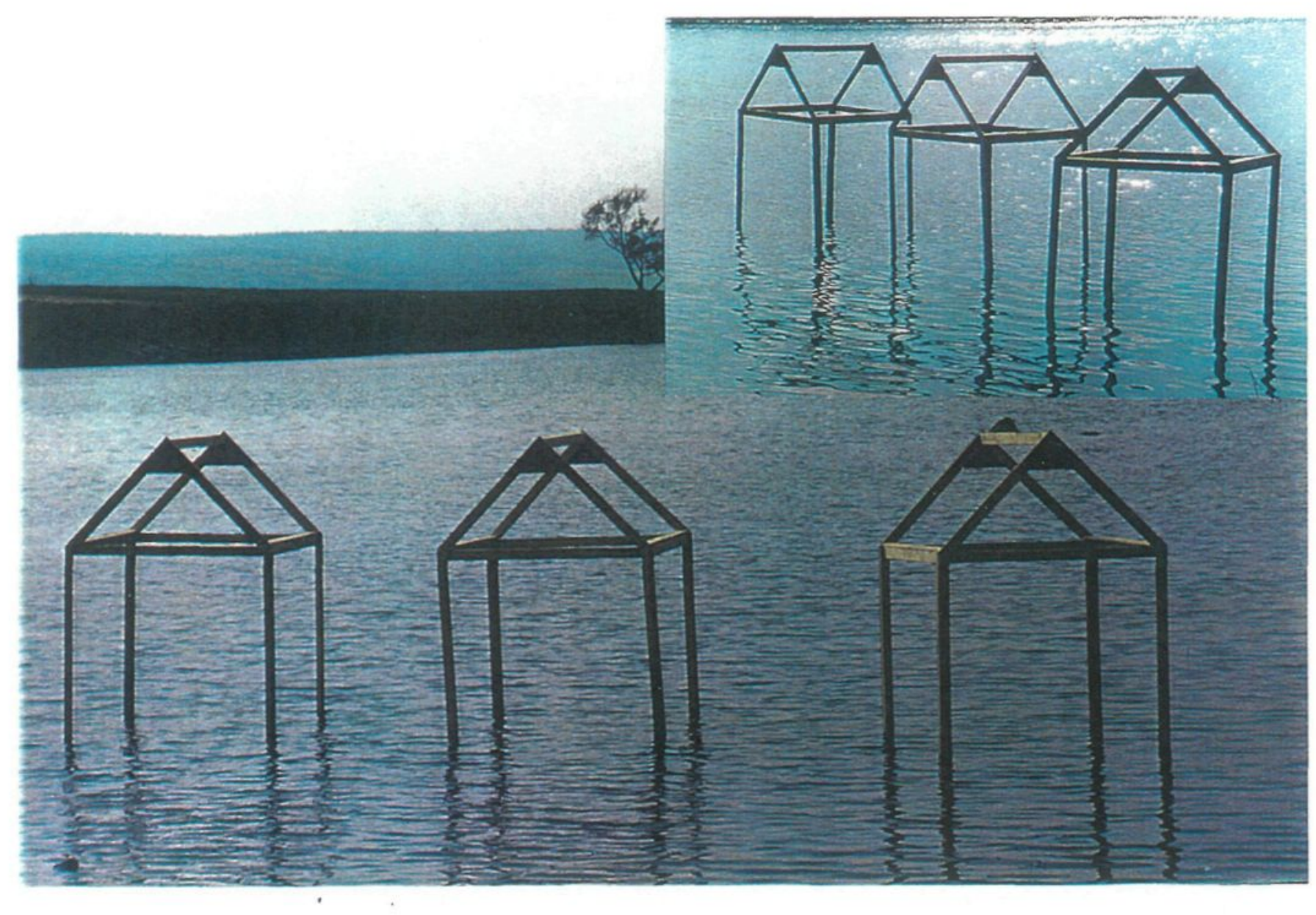




\section{NOÉ: "CAPITAINE AUX LONGS DÉTOURS"}

À la barque individuelle, le navire du collectif:

- Espace comme nécessité.

- Espace qui fait liens/lieux/noeuds.

- Espace de démesure, de débordement, de découpe.

- Espace public: accessible, plus social et révolutionnaire qu'institutionnel et fonctionnaire...

- Espace, la terre comme lien et comme lieu.

L'unique, s'il existait comme tel, en phagocytant la différence, englobe et enclôt. Le multiple, le discontinu se connaît dans le réel par la circulation: deux espaces donc chez le sédentaire: unités discrètes "immobilières" et chemins autoroutes. Ici coïncide dans le même objet un conglomérat d'éléments constructeurs et la mise à distance des éléments entre eux, par espace construit. Parallélisme de la bordée du pont du navire et du tablier du pont unis dans la même fonction intégrative. Le site de l'objet étant au trait d'union qui à la fois unit et sépare. La découpe des unités de construction fait le sens, l'ensemble de l'objet est analogue à une zone de bruit ou de tourbillon issu du paradoxe de la forme exposante fixe.

À la frontalité de la sculpture classique qui rigidifie où tourne la tête du spectateur construire une forme qu'il traverse, le situer dans le front séparant les zones différenciées de pression. C'est le lieu de la catastrophe. Le rapport air/sol/sous-sol: par l'usage du sous-sol ici littéralement le navire s'ancre. 
Capitaine aux longs détours Notre-Dame des Pins 96 


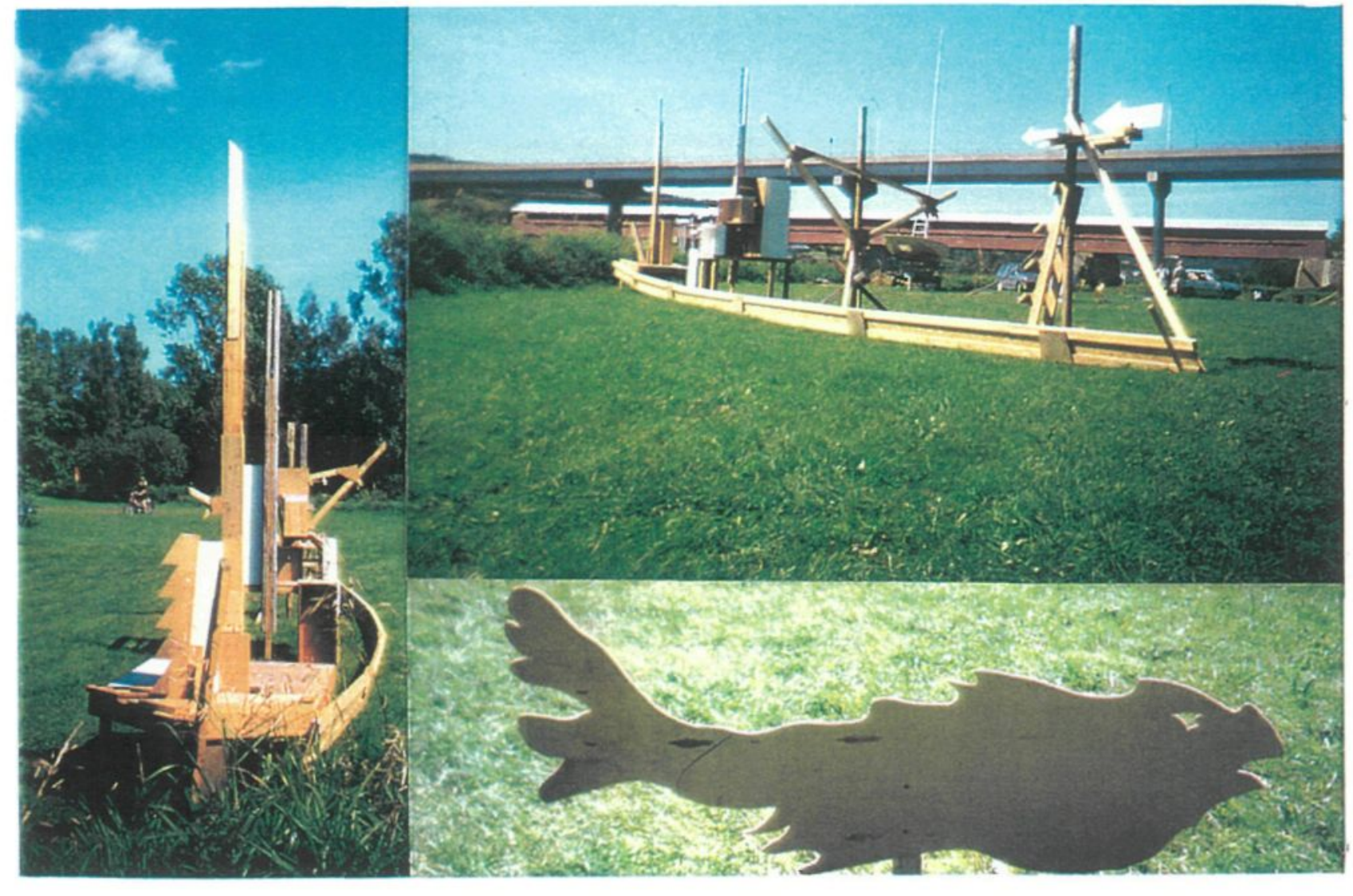




\section{NOÉ: "TON MANOIR/MON TROU NOIR"}

Ramassée sur elle-même, cette forme comme chapeau de poil, à rebrousse poil, cabane de brousse: en face, de l'autre côté de "la grande rue", le manoir Taschereau.

"Ton manoir? Mon trou noir! " Humour du vis-à-vis. Clin d'oeil au casque de poil des sentinelles: tu dors, je veille! Sentinelle silencieuse, écho de la masse des fûtaies, un peu débraillée, affichant ses couleurs, oriflammes dans le vent. Habitat de crise pour itinérant. À l'entrée, une pierre enfoncée (mini-fosse), une inscription: Comment habiter ce pays? La question.

De l'intérieur, on voit qu'il n'y a pas de toit: assurément on y dormira à la belle étoile...

$\mathrm{Au}$ centre, un montage (que la photo ne montre pas), objet solide: sur une souche inversée, érodée, figure de chapiteau, un cube en bois. Objet récupéré, c'est une "boîte à beurre". À l'intérieur de celle-ci deux bardeaux de cèdre se rencontrent à angle et redoublent le toit; endessous, un réel nid d'oiseau. Cercle, triangle, carré sur socle - chapiteau, du "grand art classique" tout en bois! Le seul meuble. De l'oiseau, je retiens sa cabane dans ma cabane et de toi, là-bas, ta cabane en fête car $250^{\circ}$ anniversaire de la ville oblige...

Architecture prétentieuse, effets de grandeur avec façade en toc et colonnes de béton. On a le château qu'on peut...Entrelacs de sapins, branches récupérées, orange contrastant avec les verts et la rivière. Le public appréciait l'économie des moyens, l'humour silencieux.

Dans "Ton manoir, mon trou noir", la réduction de limmeuble à l'abri réduit d'autant la distance entre l'effet actif de creuset et l'état passif de gîte. Bibliothèque d'une page, passage obligé du seuil de la signification: "Comment habiter ce pays". Stèle. Utiliser le bois vivant, qui se plie aux tensions, le vent qui détend le cercle tissé géométrique et s'oppose à l'organique racine à fonction de support, mobilier réduit compressé à un nid. Dire le nid pour l'abri, métonymie? Couleurs contractées dans les bandes comme la chevelure d'un drapeau rebelle, le vert de l'abri, à faible distance, se dissout dans le gazon. Tout ça situé aux marges et coïncé entre le chemin public et l'eau du large. Comme un point dense et précaire. Ne prend son envol que découpé dans la façade seigneuriale du manoir. Façades disjonctives, lui ou moi: EDN instaure la quête et commémore la maison. NOÉ "pressé d'arriver", compressé en gîte "ouvert aux 4 vents". Un noeud, comme un poing fermé...Comment habiter ce pays? Homme ivre d'un lieu... 
Ton Manoir/Mon trou noir

Sainte-Marie 94 


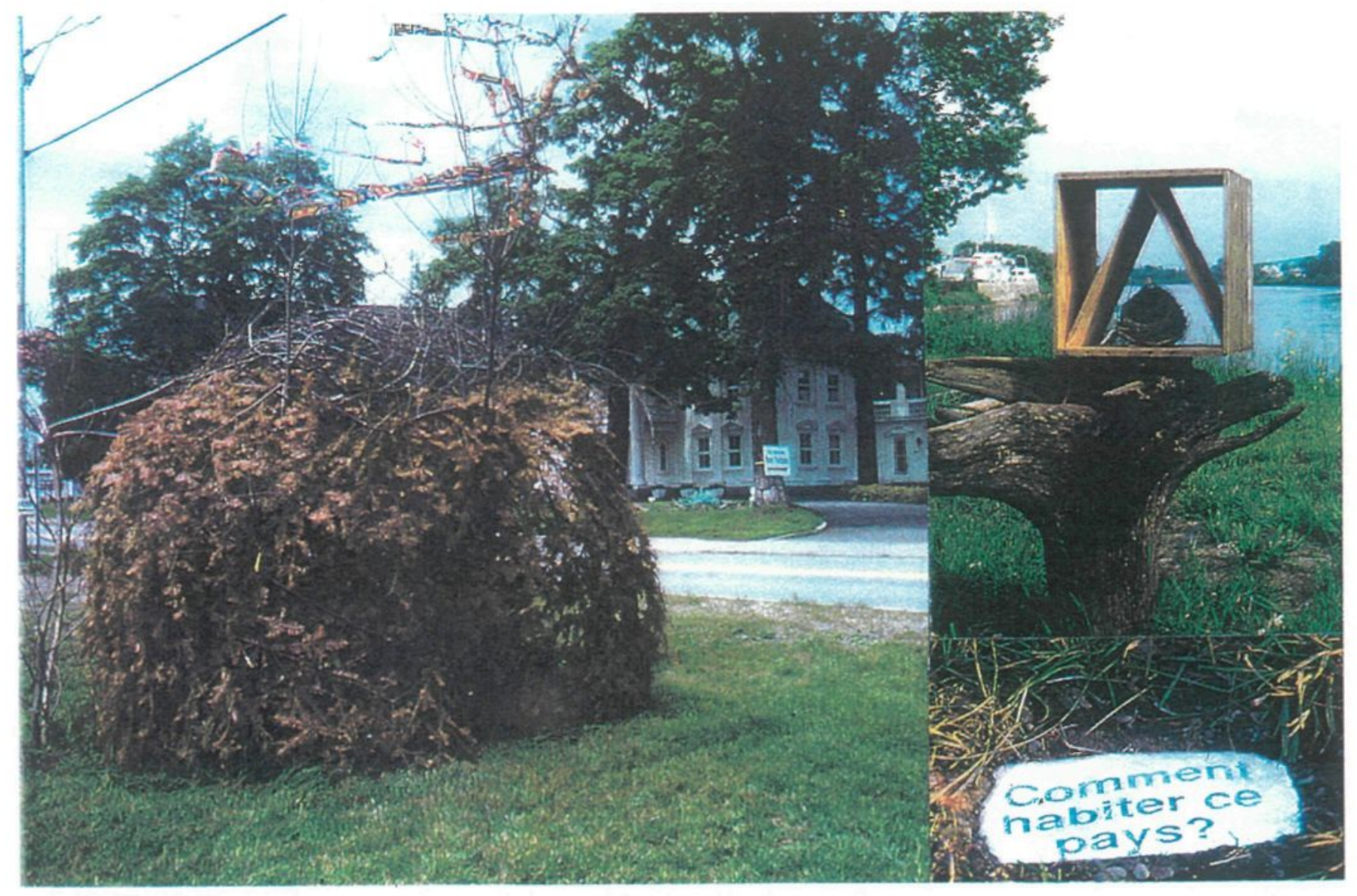




\section{III- EDEN}

Résultat d'une tension entre le sujet et l'objet, par un geste autoritaire, l'action propre d'EDN est de désigner un nom propre (dessiner, faire signe en son étymologie). À ce titre, il nomme par le verbe, il verbalise, il dresse verbalement le procès. Celui d'une marche en avant du sujet pour établir une relation spécifique. Laquelle? Communément nommé paradis - issu de l'avestique paradaïzo, son étymologie réfère à un enclos, un édifice.

EDN découpe, enclôt, ferme et donne à un site son espace propre. À s'en charger, à le prendre en charge. Il lui donne poids et solidité. L'objet désigné est assigné à se tenir debout, il résiste à son propre poids à la face du monde.

Cette opération dynamique de projeter son enceinte est grosse de potentiel. À son point ultime, elle tend à l'infiniment grand. Elle participe d'une logique associative et fonctionne sur le mode de la disjonction (et privilégie la perspective axonométrique).

La découpe de la découpe, cette opération d'enclore par la découpe établit une frontière, une marge. Éventuellement un mur s'érige en périphérie, d'où le rapport enclos/édifice: d'emblée s'instaure le rapport éthique entre l'ici et là-bas, entre l'intérieur et l'extérieur. La marge en appelle à la régulation du garde-frontière. Le maître commande la clôture...

Tu es là, moi non plus! voilà ce que raconte cette architecture qui réalise la découpe de l'individu dans l'espace réel. Dans les replis du mur, l'architecture murmure son histoire. "Dans le lit de la sculpture entre le mur et le mur".. ainsi oscille EDN. Et le déplacement de cette marge, l'agrandissement enzymatique de l'espace conquis entraîne une tension aux bornes.

Cette rupture de potentiel, ce passage à un état accru de dynamique, traverse une phase chaotique: le premier mur, ouvrage défensif, il faut le percer de portes et fenêtres pour aller aux nouvelles frontières. Le gratte-ciel vitré de miroir traversera le premier enclos de la grotte sombre et humide. La grotte décapée à l'os, l'ossature d'acier s'accroche des vitres-miroirs, éclats de ciel. Envolés ces éclats, désormais seule demeure d'EDN, la plate-forme: ce sera la plateforme spatiale! Évolution frénétique de notre architecture autour de l'oeuf primordial, la chambre. 
Cette analogie entre la perception de notre monde dans l'espace comme un habitat sur un territoire, comme une architecture donc.

EDN marque dans un premier temps, un écart: la rupture d'un mur, la traversée d'une frontière. La phase édénique procède de la logique disjonctive, elle participe à une constante d'oscillation entre l'ici/l'ailleurs: de moi à toi et d'eux à nous. Éthiquement, elle construit autoritairement la différence, elle s'érige en but différé, tel un incessant ballottement ou une course au dépassement. Elle inaugure l'aventure.

Discursivité édénique tirant sa position d'une autre position par série d'avancées successives. Elle se pose, on s'y repose, refuge temporaire du rêve. Qui ne rêve d'oasis perdu; mais nul n'est une île... On en repart. Départage, départ, portage. Pas d'EDN ni d'enclos sans porte: EDN de passage. Site de transition. Lieu nomade. Figure du voyageur, toujours entre deux rêves, comme EDN couché entre l'oasis et le désert, entre le jaune et le vert. Pour le plus grand bénéfice des agences de tourisme, on ne fixe pas EDN.

Neige. Et que fonde un espace, il y en a toujours un autre pour l'accueillir. Voilà l'important. Il n'y a pas de vide absolu. Une substitution, un spasme, une découpe se reproduit. EDN discrimine, c'est dire qu'il fixe un contour, une arabesque. Il crée un ordre à figure de retraite, d'oasis... La fonction de cette figure est de créer un écart plus qu'un sujet. Tout le contraire de la fusion: une rupture, une fission. Constamment en EDN le foyer initial se déplace à la vitesse de nos futurs anticipés. Et nos rêves fixent l'instant présent des stratégies de notre action. Découpe dans le vif du sujet, EDN donne forme à nos rêves: EDN consolide.

EDN - Tranches de vie, vie retranchée objets découpés solides aux marges des contours: artitude "borderline" d'un art de tranchée... Le vivant gravite en périphérie et mesure le centre. Par cette opération de mise à distance, en découpant le local du périphérique dans le sens (quasi histologique) d'étude régionale, ici plus que jamais le folklore "fuck l'art". C'est ainsi qu'EDN n'a de cesse de trancher et de se re-trancher dans le vif du sujet et que dans le vif du sujet.

EDN n'est pas un môle ou un pôle fixe, un objet souverain, ni la maison idéale que gauchiraient, pâles reflets, nos habitats vernaculaires. Pas plus qu'il n'a la figure lisse de l'idéale sculpture moderne brancusienne moderniste, celle de l'oeuf marbré glissant sur son reflet miroir-mouroir! 
Quel est ce mouvement aux origines? Chaos, pris au sens de tohu-bohu primordial. À travers la conscience d'un fouillis, analogue logique du stade pictural du gribouillis, l'esprit prend position en mesurant son écart. La conscience fouille, s'ancre en se fixant sur ce qui lui fait relief: une arête, une crête de rupture. Elle s'y arrête.

La sculpture est un état après avoir été un processus (de prise de conscience). Elle est un état d'esprit avant un savoir-faire, une dextérité. Ce qui lui fait aussi porter "le poids $d u$ monde".Ni en haut, ni en bas, ligne de crête ici tracée à la surface de nos rêves, EDN mouvement par lequel nous marquons nos buts à atteindre, le pôle reporté de notre itinérance. À chaque report, nouveau départ. La marge induit et elle exclut. Mouvement constant vers un futur en fuite dans l'infiniment grand.

Par cette quête constante entre deux lieux, deux régimes de dynamiques, EDN impose la traversée inopinée pour ne pas dire ,stochastique, de phases chaotiques. Elle active le chaos de chaosmose.

En tant que découpe, fonctionnant par exclusive, EDN est sécante sectaire. Fanatique intolérante à l'errance dans l'indistinct tohu-bohu, elle est l'état premier de mise au monde d'une forme.La mesure d'EDN est la mesure d'un écart, de ce qui s'écarte du sujet. Ainsi commande-telle l'autonomie formelle. Directement proportionnelle à l'affirmation du sujet, c'est dans l'ivresse de l'abus du pouvoir qu'elle vacille dans la dichotomie. Disjoncteur, EDN fonde le sujet. En le nommant (le "Verbe") il instaure dans l'objet la fonction commémorative. Elle disjoint, elle disjoncte. En éclair, EDN s'éclate "péter les disjoncteurs". Son cheminement est théorie au sens de parade de formes. L'écart de l'écart.

En tendant davantage à souligner ce qui fait différence dans un lieu et d'un lieu à un autre, EDN raconte une probabilité de localisation, une configuration plus qu'un lieu fermé. C'est le lieu privilégié de l'arabesque.

Dans cette course vers le toujours plus loin, la longueur d'EDN est celle de toute la profondeur fatale. Plus qu'une figure générique de l'enfance de l'art, EDN est moins un lieu que le rapport entre le lieu du sujet et son objet. Traçant une marge entre le réel et son mythe, forçant par son passage le chaos de chaosmose, par sa logique disjonctive exacerbée, EDN est moins l'écart à ce lieu que la mesure de cet écart. 


\section{BABEL}

L'enclos de l'enclos qui se replie en lui-même. Image d'une suite de réflexions intérieures où l'objet se mire, narcissiquement, sur le report de sa propre image. Réduction du signe vers la schématisation de la signalétique. L'inclination de certaines formes à se reproduire, à s'autogérer, à se surcoder par l'usage: site, signal, schéma, toujours persiste le signe...

BLL - Babel dont le plan d'origine est une contamination d'EDN; le ziggourat s'érige en excroissance d'un segment de jardin, sur plan carré. Une forme d'itinérance qui se crée son chemin dans le retour sur soi. Forme insistante, incestueuse de BLL. BLL ou l'incessant pliage incestueux du jeu de je, à moi vers soi...

Le redoublement, la pliure sans découpe, sans cassure: miroir, reflet. En ce sens, l'objet se rapetisse, s'écrase et perd de sa grandeur, laminé par son auto-réflexivité: se révèle alors en son centre ce qui résiste dans un objet. Sa part structurante. BLL entendu comme suite d'autoréflexivité en forme d'itinérance ouvrant le chemin vers un autre objet.

Ce qui s'enfuit et ce qui reste. Ce mouvement interne de subdivision de soi en déroute vers l'infiniment petit d'une part même si, d'autre part, ce qui résiste au fil des déplacements réflexifs se retrouve aplati, laminé en son amplitude de sens par l'érosion répétitive du quant à soi. Il en est de BLL comme d'un incessant repli, un "exil intérieur"!

Front de taille, BLL se donne en spectacle comme horizon indépassable...en met décorativement plein la vue et se ferme sur lui-même. Ainsi de BLL chantier en devenir perpétuel. BLL travaille. Là où EDN découpe, BLL plie et relie. Il intériorise l'écart d'EDN, se le plie, se cache en la charge de ses replis, y trouve son sens de direction et sa pesanteur: transe, transhumance et résilience.

L'affirmation entêtée de la réflexion récurrente produit une cohésion interne de la signification et l'objet y acquiert densité, opacité et solidité. D'où cette fécondité endogène de BLL qui parle d'émergence, de croissance en ses replis. 
BLL piège pour le regard puisque le principe circulaire qui préside à son auto-construction, se conjugue impérativement avec la nécessité intérieure d'y circuler. À moyen terme, effet fascinant de BLL réduit au motif. BLL s'y multiplie dans la fonction décorative (refoulée du modernisme). Formule séquentielle et/ou sérielle de son principe de construction.

Là où EDN, par sa transition de phase du chaos se met K.O., se case, BLL lui s'écrase. C'est l'osmose de chaosmose. C'est ici la pente naturelle de certaines formes à se reproduire à s'autogénérer en se surcodant (syndrome Walt Disney).

Dans sa fuite en avant BLL parfois fonctionne par rupture d'échelle. Répétant inlassablement la subdivision infinie de lui-même, il cristallise la catégorie fractale. Ainsi compris, il devient le lieu de cette première assomption, celle de la complexité radicale de l'espace vernaculaire.

Le pli du pli dans le repli, c'est maintenant la structure qui devient signification et se crée en nouvel objet. Ce chemin faisant, je est toujours un autre un peu plus gros de lui-même! L'autre apparaît, ancêtre mythique. C'est en BLL que le grain de sable devient dune et appelle l'oasis (EDN). Que la cellule devient organisme familial (en déroute de NOÉ comme BLL et EDN) et ici l'arbre de BLL témoigne de sa forêt. Ainsi se crée un tout différent de ses origines par répétition abusive de sa singularité.

Souligner "l'effet hambourgeois" de BLL, c'est-à-dire sa logique d'implication. Savoir que sa dynamique interne spécifique consiste à s'auto-structurer selon un principe spécifique et soumettre ses matériaux autour de cet axe architectonique. Un certain rapport dedans/dehors en BLL: unidimensionnalité d'un axe structurant à l'interne. Fracassement décoratif par module et série à l'externe. C'est le continuum dans cette volonté de plier le réel qui caractérise BLL: soumettre à terme le réel, tout le réel à sa relation d'inférence. Caractère visqueux de cette logique qui opère par contiguiité: "Ça se tient en vérité parce que ça colle dans le réel".

Dans une figure de Mandelbrot comme dans un ziggourat, c'est le principe fondateur qui résiste, conduit le chantier, laisse des traces impérissables (subsistent de la BLL d'origine suffisamment de fondations pour sérialiser l'ensemble). Chaque stade du développement définit les paramètres du stade suivant dans une logique interne qui plie tout rigoureusement. Par extension parler d'une bobine de fil comme un BLL en rouleau et d'une piste d'avion comme BLL au repos. En effet BLL ne s'érige pas par l'affirmation itérative d'un vecteur, axial fût-il vertical et ce n'est 
pas en prenant le contre pied de l'attraction d'un sol qu'il s'élève, c'est "à rebrousse poil", par la cohésion additive de son cheminement dans sa structure interne qu'il déplie son architectonique.

Pli, dépli et repli. Duplication, complication, BLL réside et se cache dans ses plis. Initiation du labyrinthe à figure de montagne. Plus que l'image d'un axe vertical, lieu du bond qualitatif, c'est l'abus de la continuité qui crée la différence. Là où le passage réitéré de strates analogues de significations permet de raconter l'épopée de la traversée du désert... C'est en établissant une différence par scissiparité interne dans la continuité de son propre redoublement qu'il s'érige (implicare: plier dans). Sa fécondité réside dans son potentiel de relations d'implication où un principe retenu se reconduit en chacune de ses sous-parties, structure auto-organisationnelle. "Là où EDN découpe, BLL relie". BLL s'érige par la division à l'infini. La définition de BLL comme catégorie fractale est la première assomption de la complexité radicale de l'espace vernaculaire. N'ayant qu'un tour en son sac, en ses multiples retours et sans détours BLL est plus qu'une tour rouge! Ainsi compris jusqu'où peut s'élever BLL sinon jusqu'à sa hauteur fatale, fatalement. Rempli de souplesse et docile parce que pliable, BLL se fracasse contre l'inflexible noeud de NOE.

Observatoire (Terre Plate II)

Granby 95 


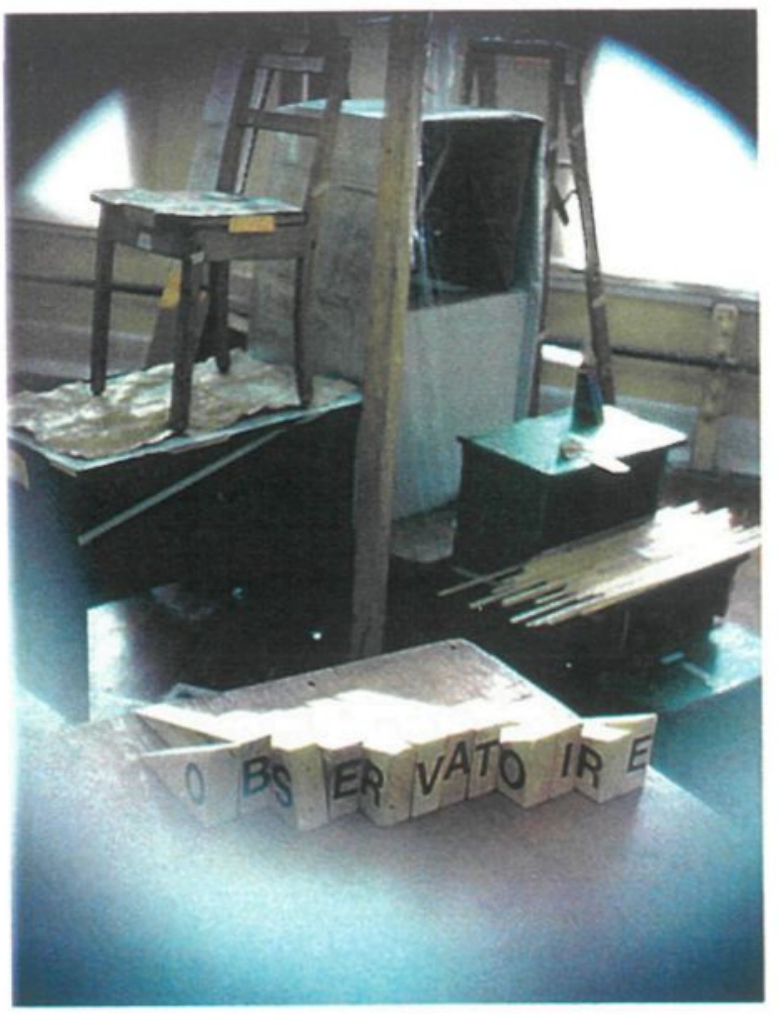


NOÉ

Arche de Noé, arc-en-ciel. Comme on dit: "S'asseoir entre deux chaises", "entre la peau et les os", "entre deux eaux". Entre ce qui l'harmonise en l'abritant et le transporte sur la flotte, tout comme glissant sur la sève d'entre l'arbre et l'écorce... Sur sa coquille de noix, dans son caisson surtendu entre ciel et terre, passé à la grosse caisse, dans son coffre, dans son arche, dans son oeuf, dans un noeud et les tripes nouées, ainsi nous apparaît NOE.

Sans queue ni tête, labyrinthe lové dans le germe d'un monde. Un monde ramassé sur luimême comme complet, image autosuffisante de sa totalité: une île à la flotte. NOE coïncide avec sa propre finalité, monde compressé, il est sa destination fatale. C'est un événement extérieur à son système qui l'assigne à résidence: que l'eau se retire et l'équilibre est rompu.

Pour l'instant NOE bleu flotte entre deux eaux, entre la réalité d'un monde qui se déverse et l'assignation à une mission mythique. Sauver l'humanité, rien d'autre! L'état d'un complexe chez NOE qui est celui de la dérive comme figure totalisante. Étrange silence des exclus! Il noie allègrement dans les tourbillons de son sillage les cris horrifiés des couples que son arbitraire a décidé d'ignorer. En s'installant en point d'appui de l'humanité future il se veut sans mesure le maître étalon de la sélection naturelle des espèces en devenir. Dérive éthique commune à ce navire en détresse. Vie, déviance! Écartée de sa destinée multiplicatrice pour un court instant, l'humanité fondamentale se raconte le mythe par lequel elle se serait créé son oeuf primordial. Le prix à payer? Une bagatelle! Rien de moins que le risque de sa disparition.

Pour surligner sa trace héroïque, lorsque passe NOE, c'est l'humanité entière qu'il écarte de son présent et dont il intègre en son corps la destinée future. Comment survivre lorsqu'on ne maitrise pas les éléments sinon en se construisant un niveau d'ordre supérieur au désordre ambiant. En donnant une logique interne aux éléments qui soit cohésive et résiliante (qui absorbe et réponde à l'agression). Le réel dans ça? Le fait est le réel: la flotte tombe, l'arche flotte!

Ne faut-il pas que tous meurent pour qu'un seul soit sauvé? Création par le vide. Remplir en faisant le vide, impose la figure du transporteur. C'est dans l'océan de larmes de la multitude 
humaine catastrophée que navigue NOE. Étrange figure du récit qui pour monumentaliser l'épopée rassemble et compresse en un ouf point, noyant la bio-diversité dans un cataclysme océanique...

Dans NOE, la logique intégrative se trouve fixée pathologiquement sur l'association réductrice par le couplage des individus, dé-route littéralement. Entraînant la déviance éthique, elle menace de conduire toute la mission vers l'effondrement global. Plus qu'en n'importe quel ailleurs, ici en NOÉ littéralement l'humanité frappe un noeud.

Dérive, dé-lire : Avant/Après. Deux états, deux moments sur l'axe temporel. Lorsque pour un même objet donné deux états de dynamiques ou de signification s'ouvrent en carrefour, alors se produit une bifurcation. NOE tangue sur la mer avant d'inventer l'ivresse.

À première vue pourtant une chose toute simple, une "mise en boîte", c'est l'arche et une solution simpliste, des couples uniquement. En "rang d'oignon" et "deux par deux". Énumération, degré zéro de la construction. D'une situation simplifiante à l'origine et où tout flotte et tout baigne dans la flotte et pourtant on en parle de façon nouée, nodale. C'est le récit qui dérape: sinistre, une catastrophe prend visage, solution qui capote en démarrant. "Solution finale " s'entend... Un noeud, un noeud coulant s'infiltre ainsi dans la marge étroite qui sépare l'événement réel du mythe. À défaut de boiter, ça chaloupe.

NOE, carrefour en transhumance qui temporairement se prend pour la planète. NOE paranoïaque. Noeud, lieu-dit de l'espace restreint, contraint. De cette complexité, il faut s'appeler NOE pour ne pas se faire de complexe! Et le pied marin pour ne pas vaciller dans l'horreur de ce vide... Imprévisible NOE qui ne s'achève pas d'en finir, toujours ballotté de débarquation en bifurcation. Cette volonté du noeud à vouloir se fixer "à tout jamais.". Le noeud généré par le point en dérive, le simple génère le complexe. D'où construire un objet complexe est l'équivalent de construire un noeud.

Le point non comme forme exclue dans le triangle perspectiviste, fuyant dans le passage limite à l'infini, mais comme forme de l'illimité dans l'infinie distance et génératif de la diversité. Le nodal emblème du paradoxe: le simple génère toute complexité. Le passage à la limite est le lieu de la catastrophe. Ces étoiles où nous n'irons jamais et qui nous sont invivables. Au point se pointe l'infini. L'infini comme forme de passage limite. 
Au risque d'ériger un noeud neuf, si tant est qu'on le perçoive en rapport externe/interne, l'intérieur poli en oeuf, parler alors d'enveloppe, parler de surface qui se granule et s'érige en texture de ce sujet vide. D'évidence, tout ce qu'il y a de construit sur ce qui s'y évide, de ce qu'il y a de constriction dans cette construction qui tend à s'enlever en s'élevant (construction; struere: élever), à s'y structurer avec acharnement dans ce qui tend à faire rapport.

En deçà donc. Plus près de son objet. Point noir/trou noir. Opaque au sens, le noeud fait le vide autour de lui. Résistant à l'analyse, il absorbe douleur et couleur; il ne réfléchit pas! On le tranche. Réponse simple à la voie simple de NOE. Qu'il flotte à notre horizon, signal de détresse, son arche monumentale annonce la catastrophe imminente. On la fuit (infiniment...).

L'essentiel théorique de la réflexion sur les catastrophes ne tient-il pas en la capacité à ramener - "à ramer" - à travers les discontinuités apparentes la lente évolution d'une manifestation sousjacente. Milieu aquatique, mathématique qualifiée par René Thom de front d'onde, capable en un poissonneux filet de se courber, d'attraper des accidents divers et subir de multiples transformations.

Matière grise

Chicoutimi 95 


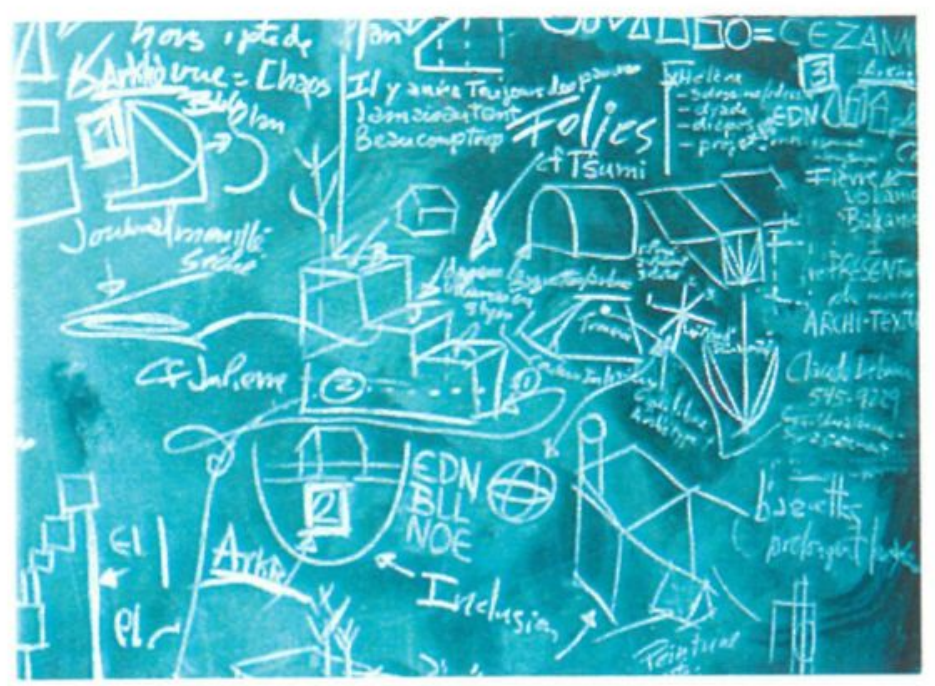




\section{NOUER}

Quand le noeud se fait verbe, il noue en lui et se noue ici le futur de l'humain (c'est le récit qui fait l'homme). Situer en NOE l'émergence de l'auto-organisation: celui qui se prend en main. "Ya toujours eu des pauvres... oui mais jamais autant".

Peut-on imaginer un point fixe autour duquel prennent appui les forces en contradiction au centre du noeud. La masse homogène d'un matériau quelconque se présente de soi comme de "l'anti-noeud". La première s'assemble, échelonne sa gravité autour d'un point de référence stable en son centre. Le noeud piège, rassemble l'hétérogène arbitrairement. Là où le premier "fait simple", le second est compliqué. La masse peut se développer démesurément, son point référentiel se déplace vorace: masse cancéreuse, anti-point. La masse exclut l'hétérogénéité là où le noeud la raccommode et se la rassemble.

On peut bricoler la masse mais pas de noeud qui ne soit construit. La masse est quelconque là où le noeud est singulier. La masse est d'énergie centripète là où le noeud enlace dans l'espace. La masse a gravité centrale, elle est grave, elle cherche ancrage. Ce qui joint l'hétérogénéité, aberrations et tératologies sont nodaux. Le noeud rassemble en un même lieu flottant un troupeau disparate d'éléments accouplés. Peut-on voir le trou vide comme l'anti-noeud? Ce noeud tire à lui la figure de l'oxymoron.

Noeud, qui rassemble une masse d'éclats en passe de s'éclater! À la masse comprise comme matière compacte, bornée que frappe et perd l'outil, substituer une masse de dynamiques fragiles, aléatoires et interreliées. L'angoisse du vide s'y comble. Qui a dit que l'homme était l'analogue d'une équation linéaire?

Coincé, ramassé, écrasé entre les eaux d'en haut et celles d'en bas et la coque refuge et le pont couvert abrité sur le miroir déchaîné, NOE erre, contraint. Terme ici on ne peut plus approprié puisqu'en mécanique on nomme ainsi la grandeur qui caractérise l'intensité des forces de contacts superficiels. Dans cet axe de symétrie - compression de la tension - qui l'harmonise, NOE jette l'ancre... et son navire, lui, vogue à la dérive! On ne doute pas d'un noeud, il nous frappe ou on lui tranche la gorge. 
Contraint, NOE rêve de sauver sa peau servile aux éléments. BLL est un projet de se conquérir logiquement, de se cristalliser jusqu'en ses éléments les plus intimes.

En NOE le refus du fatalisme se reconduit par le fanatisme: le rejet de la foule entraîne l'enfermement par le biais de cette sélection d'élus (lesquels en général sont phantasmés en cages...!)

Les espèces dès l'a-bord précontraintes de s'embarquer en isolation, en île artificielle, en réponse aux éléments contraignants de la nature. Stratégie de NOE: la précontrainte augmente la résistance du matériau équipage. Ainsi du noeud, oeuf précontraint.

Tandis qu'on quitte ou rejoint un paradis, alors qu'on construit ou jette à bas une tour, il faut choisir son heure: éthiquement la preuve du noeud est dans l'épreuve de le trancher. Ce qui n'enlève rien à la flexibilité des éléments dans le noeud (noeud qui joint et joue dans ses articulations sans quoi ça casse). Réversibilité conceptuelle des éléments du noeud: ce côté sans queue ni tête. La folie du noeud complexe. Folie s'entend par monde "à l'envers et contre tout". "La Croisière s'amuse " et La Nef des Fous.... (titre du premier best-seller occidental, ouvrage de Sebastian Brandt). Qui défile à quelle vitesse, qui file à combien de noeud? La vitesse du noeud fait noeud: le noeud défile, les sens s'enfilent... Où est le noeud de l'arche de NOE? C'est toute l'action qui fait noeud: embarquement panique, navigation erratique, naufrage en haute montagne! Dans la mouvance d'EDN BLL, NOE est le point essentiel d'une affaire complexe, l'action à son point culminant.

Sainte-Aurélie

Sainte-Aurélie 96 


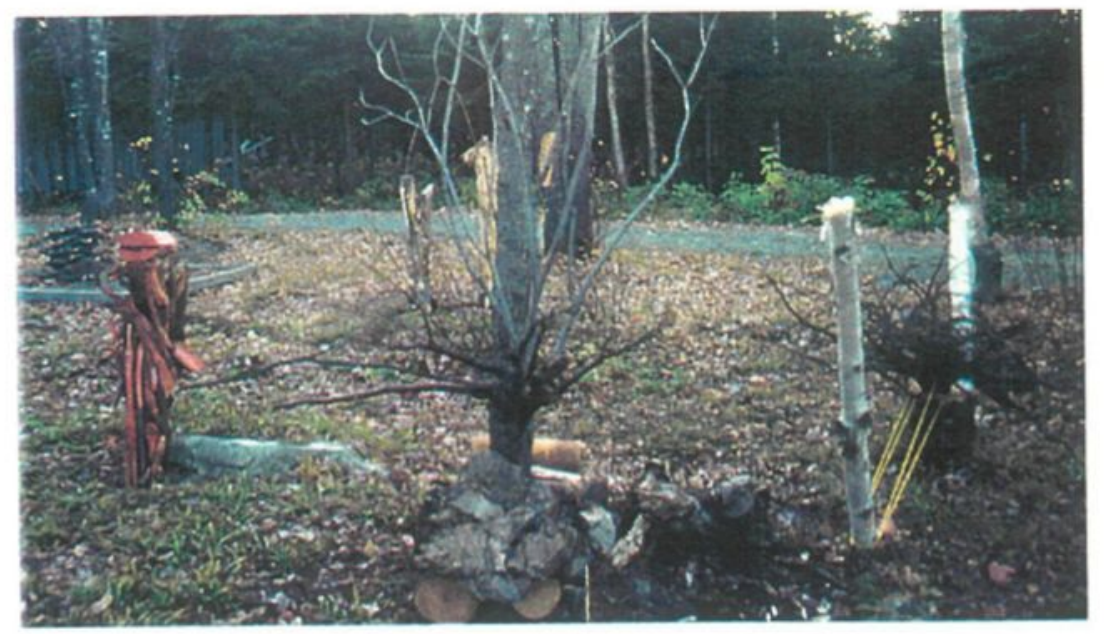




\section{NOEUD}

Noeud, labyrinthe à entrées et sorties multiples, à la croisée des chemins. Lieu d'embranchement où se croisent plusieurs lignes de vie: NOE carrefour flottant.

Point rond à l'horizon ici rond-point, site et rite de passage. Lien de transition, des rencontres contrariées. De la rencontre des contraires. "Frapper son noeud". Là où on rêve d'un EDN écologique, BLL est construction logique. Le noeud est un assemblage. BLL chemine, NOE ballotte, bifurque et danse au carrefour des eaux une valse hésitation. Carrefour insensé, la logique ballote et se signe une contre-danse.

La résultante des forces actives complexes au sein du noeud le met à la question, le travaille au corps et le pré-contraint. Le noeud prenant son envol. Le noeud vole à la vie sa complexité. Le noeud fait violence au "bon sens commun". Par sa résistance, il appelle à la violence. Forme voilée au sens, le noeud est une forme violente. L'espace du noeud coïncide avec l'espace du viol.

Sur l'onde, portés par les vagues autour de NOE, débordent les torrents du déluge, les flux d'énergie déferlent: pour avoir emmagasiné ses réserves le noeud résiste (les batteries chargées, "tant qu'il y aura quelque chose dans le frigidaire..."). Avec assurance, comme le dernier carré, il se localise, se globalise dans la résistance. Affrontant glorieusement les éléments tel un monument autour de lui, il fait le vide. Là où BLL est en chantier permanent, le noeud est une construction achevée: sous cet angle comme une réponse simple à une question complexe.

Noeud d'énergie. Forme finale d'énergie terminale. Finitude.

En constante isostasie, dans l'arche de NOE l'horizon du sens coïncide avec la ligne de flottaison. Horizon nodal, surface vibrante.

La force intérieure du noeud, son intégrité, "plus blanc que blanc", charge le sens et casse la tête. Pourquoi? La logique intégrative et l'intégrale d'un sens donné dans un noeud. 
Littéralité des rapports d'intégration (non seulement toute recherche se veut intègre mais la recherche du tout, la tentative de créer de l'unité conjugue dans un même mouvement intégrité et intégralité, tout uniment facteur dintégration. (Recherche du pouvoir sur sa vie, donc stratégie, éthique: réaliser sa vie comme art). Littéralité/intégralité.

Le cerveau humain est un noeud, il trouve là "chaussure à son pied" "à qui parler"... Le noeud s'installe d'autorité; prenant de la place, il fait le vide autour de lui: il s'asseoit au seuil limite du lieu des catastrophes. Le principe d'incertitude, "ce sans queue ni tête", ça flotte autour de NOE comme le sens/linsensé flotte dans le noeud. La solution incertaine au noeud de la question. Irrésolution, flou fluctuant: on frappe un noeud. Arche de NOE, sacré party, bal flottant, pavé dans la mare, dalle flottante, mouvement fondateur d'une humanité en déroute. Lorsque pour un même objet donné deux états de dynamiques ou de signification coexistent, alors s'ouvre un carrefour, une bifurcation... NOE tangue sur la mer avant d'inventer l'ivresse... NOE dans sa déviance systématisée est créateur d'aberration, de singularité. Il nous ressemble.

Ton Manoir/Mon Trou Noir Sainte-Marie 94 


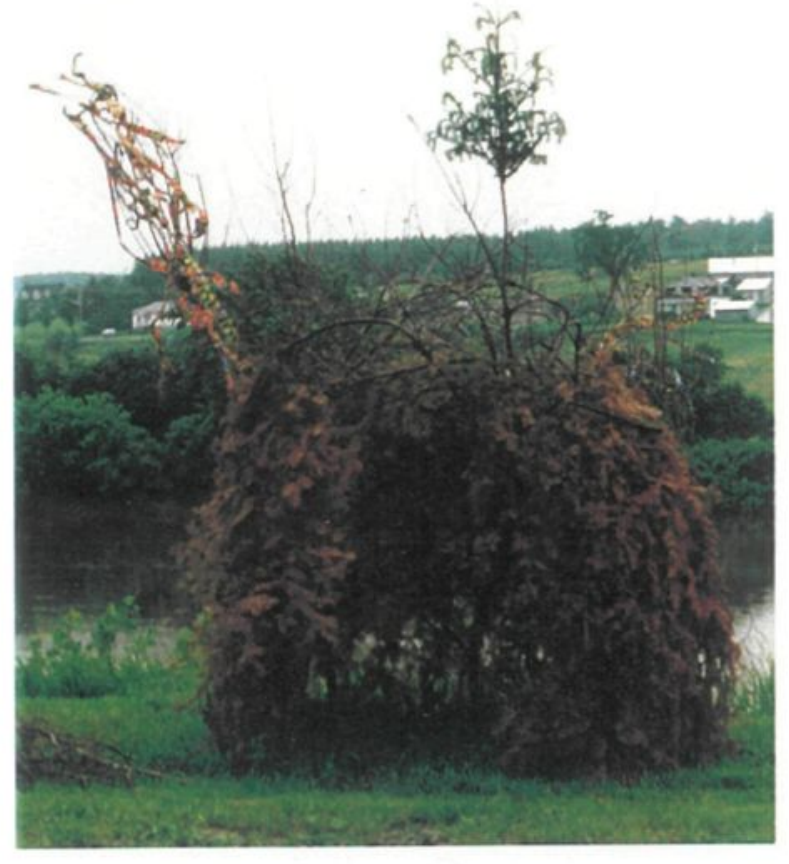




\section{CONTEXTE/COMPLEXE}

Nouer c'est "organiser une affaire compliquée". Réponse on ne peut plus appropriée à une question complexe. Pour NOE, le noeud est avant tout une solution à un problème posé. Étant donné l'arche de NOE, "pré-texte", "affaire bouclée"! Et que vogue le navire, affaire entendue! En nouant, on arrête la fuite insensée du sens, on s'unit avec soi-même, on se lie organiquement aux éléments.

Complexe, de plexus, entrelacement, de "plectere", tresser: c'est en réunissant des éléments différents (noeud contenant - arche, boîte) - qu'il est complexe. Il se présente comme un ensemble global (simple en apparence, constituants disparates). Un panier de crabe en réalité et c'est le panier que l'on retient! NOE? Coffré dans l'arche, boîte de Pandore.

Il est compliqué: roulant et entortillant ses éléments disparates, il en obscurcit la direction du sens au profit de la charge affective, de l'effet total, final. Le total "le final" font lisse, et simple à l'esprit et s'opposent au complexe. Dans les méandres du noeud, la signification risque de se perdre. NOÉ est une réponse complexe à une question simple de survie. Le noeud une réponse simple à une énigme complexe. Le noeud de Noé, une réponse complexe à une question complexe.

La logique intégrative du noeud réside en sa faculté de s'installer comme vortex d'énergie. Dans cette tension active qui vise à s'adjoindre la série pour s'amplifier. Noé en incessants ressacs de bifurcations, ici des couples deviennent instruments d'accès à une totalité. De je, à toi, à nous, à $e u x$ vers l'infiniment complexe. Dans ce geste rassembleur, par l'intégrale de sa solidarité, la dimension de NOÉ c'est le rejet de toute la fatalité. Le noeud cherche sa propre fin, il est en projet d'autonomie. Il s'organise en complexité et fait entrer en lui ce qui lui est extérieur. Le noeud répartit ce qu'il est, un projet de totalité, un ensemble. Il ordonne ce qui gravite autour de lui en sous-ensembles, temporairement parties, qu'il cherchera à s'impliquer pour se totaliser. Ce faisant il instaure dans l'objet la fonction monumentale.

NOE - Le risque génétique - attracteur étrange du chaos - de former des objets aberrants. Fécondité de ce qui, tout en s'écartant régulièrement de la normalité, présente de rares et singulières variations. NOE devient principe auto-générateur d'écarts (capitaine assagi/alcoolique déclaré...) 
Il fascine, on le fuit, il nous déroute. Pour se donner cohérence, il se structure, s'organise, se construit. Une maison est un noeud et flotte aux avatars saisonniers. Une télévision par ses circuits nodaux offre sa surface simple comme écran paranoïaque de nos phantasmes.

Force entropique du noeud. Il comprend plusieurs éléments et surtout se comprend lui-même. Il ne livre pas aisément son intelligibilité à un agent extérieur. Stratégie nodale, il se rend flexible pour mieux se circonvenir, se circonscrire et résister à la fatalité.

Bricole-t-on un noeud? Un noeud est un ensemble construit.Et l'homme se fit un réel à son image: un noeud. Le noeud se compacte à un seuil spécifique, un ordre donné de réalité. Il se donne son espace et tout le réel de cet espace. Comprendre en deçà de ces généralités que le noeud est une maïeutique agie, une dialectique en marche. Intègre au sens d'incorruptible, le noeud ne se livre pas aisément, il résiste à l'analyse autant qu'aux éléments. C'est l'opacité du noeud. Le noeud "A LES BLEUS".

Qu'est-ce que le passage à la catastrophe chez NOE? Quels en sont les effets dynamiques: un bouleversement, un désastre "mauvaise étoile" (ateliers éclats). Une chute de sens dernier et principal avènement d'un poème: ce qui marque une fin.

Dans la catastrophe, un cycle s'achève, un cycle tourne. Ainsi donc et brusquement, dans l'instant (passé/futur: présent, direction de la compression du temps) l'événement noué verse, se déluge dans la catastrophe. Le nodal n'a plus sa vigueur, il se relâche. Le "diable est aux vaches", "les quatre fers en l'air".

Dans la dérive du sens, pour maintenir le cap, NOE conduit la déviance. Il est stratégiquement efficace à défaut d'être politiquement correct. Il n'y a pas de normalité au noeud. Le noeud est spécifique. Monumental, il évacue les autres propositions et se donne pour lui-même. Opposé à EDN, loin des marges, des rives, opposé à BLL qui bouge certes, mais défile à l'intérieur de luimême, NOE navigue dans la dérive et résiste à l'érosion par le complexe de ses entrelacs du sens. Sa logique est de se configurer intégralement autour d'un centre de résistance en marche vers l'infiniment complexe et c'est tout le cosmos de chaosmose qu'il active. 


\section{IV- EBN "ARTEFACT DU PATRIMOINE MONDIAL}

EDN BBL NOE. EBN forme compressée. Ces termes d'Eden, de Babel et de Noé déterminent l'objet, et à l'intérieur de l'objet les caractères de la dynamique propre qui s'y travaille. Trois espaces, trois structures d'installation. Dès lors, se profile et se sous-tend une conception de l'espace. Ce ne sont pas des images, mais "les cas de figures" de dynamiques précises. EBN métaphysique de la perception et phénoménologie d'un espace.

Ce qu'entraîne la mise en rapport des trois formes structurantes de base est un produit complexe. Chacun des régimes de dynamique s'y compresse. Pour y voir clair, une coupe séquentielle s'impose. EBN se donne à lire comme un texte et à voir comme une texture. Entre ces deux opérations, le sens s'y stresse et s'y tresse. Texte, trame, tissu. Dans ce drapé du texte, dans ce drame quelle énigme se trame? On se "balade", NOE; de la ville, BLL; vers la campagne, EDN. Déjà, les figures sont ordonnées par séquence dans le récit d'origine et le parler populaire les en détache pour mieux relever, voire épicer une tranche de "petite vie": "On était si bien, un vrai paradis". "On se comprenait plus, une vraie tour de babel." "Y pleuvait, un vrai déluge".

C'est là que la transitivité s'oppose à l'opacité et produit la beauté et l'émotion esthétique. Là où EBN se subdivise en autant de groupes isomorphes. Des parentés s'y relèvent; l'objet produit tente de clarifier ces combinaisons, ces liens de parenté. Il fait du sens. Et la texture étant la dernière frontière épidermique de l'objet, ici la singularité tient dans un niveau interne par la disposition des éléments.

Toutefois, à toute échelle, dans le pli du pli c'est la structure qui s'affirme. Un flocon plus un flocon, une brique plus une brique, ce sont les effets "mur de brique" et "banc de neige" qui s'imposent. Distinguer ainsi et le nom et la chose en acceptant de "voir les choses en face" (ce qui incorpore et dépasse la question de la frontalité en sculpture, qui de moins en moins se tient debout et qui n'ayant "ni queue ni tête" ne clone pas le regardeur pictural). Un visage "à trois faces". Et ce, en ayant toujours à l'esprit un objet réel, dès l'origine trace d'une chose solide et concrète, EBN ne présentant que du connu, de l'archi-connu. 


\section{EBN : UN PLAISIR EN TROIS ESPACES}

Tel est l'axe du plaisir qu'en EDN, l'offre précède la demande et le désir y est censuré par l'autorité. En BLL le besoin s'exprime et la demande égale l'offre, mais le désir se subit sans plaisir. NOE exprime un besoin, un désir, qui dans un naufrage aviné, trouve son plaisir. On dira alors que dans le texte le plaisir est pré-contraint dans la forme d'EBN. Il est mis sous tension et sert de force constructive.

EDN marque le départ d'un lieu, BLL l'apprentissage par la répétition, NOÉ inclut le sujet autonome dans le processus. EBN comme ensemble figure l'accomplissement en marquant un mouvement interne d'itinérance, c'est-à-dire constructif parce qu'en mouvement dirigé.

EBN - La découpe régulatrice d'EDN par laquelle "les choses se mettent à leur place...". Ainsi compris, EDN correspond à l'espace des fondamentalismes et ce qu'EDN gagne en expansion, le "non EDN" le perd. Il s'agit de l'espace fromagé traditionnel fait de plein et de vide. Espace de construction à somme nulle, c'est l'analogue du système autoritaire de la Tradition.

D'autre part, autant BLL se développe, d'autant cette nouvelle construction se déroule en espace systémique. À la limite, il ne lui suffit que d'un point d'ancrage pour se fractaliser. Composé d'éléments fractionnés, séparés, indécomposables à leur niveau hiérarchique, il s'agit d'un espace hyper discret, construit sur l'auto-référentialité. S'y retrouvent les caractéristiques modélisantes de l'espace moderniste.

Autant la découpe est instantanée au niveau du faire et le pli un processus, d'autant le noeud est une incertitude... NOE s'offre comme un espace autonome, sans ancrage et flotte à la dérive. Il s'érige en identité propre, lieu privilégié de l'auto-réflexivité. En mouvement de constante adaptation avec son environnement et entretenant une relation féconde avec lui-même. Lieu privilégié de l'espace compressé et gîte de l'émergence. Espace post-moderne.

Voici les dimensions spécifiques de chaque figure: - oscillation de la disjonction en EDN - accumulation de limplication en BLL - prolifération de l'intégration en NOÉ 


\section{EBN: UNE CHAÎNE D'ESPACES SURDIMENSIONNÉS}

EDN nomme et découpe, devenant lieu de l'énumération de formes, il donne leur signalement. BLL les classe, les distribue, les accumule. En NOE, elles s'y cristallisent et font corps turbulent.

Par la déroute d'EDN, l'exil intérieur de BLL, le tourbillon de NOE, l'écart à la norme comme forme générique de mouvement s'impose.

En EBN se travaille une proposition d'environnement hors de l'économie du reproductible (la famille est exclue...). La trame du récit d'origine étant ENB, la séquence EBN inscrit un repli stratégique. EBN installe tout contre la fatalité autoritaire du Livre, la Bible, le dispositif stratégique d'un espace de jeu.

Ritournelle: dans la découpe d'EDN produite par le déplacement d'une surface produite par le déplacement d'un axe produit par le déplacement d'un point; dans le pli de Babel produit par le déplacement d'un axe produit par le déplacement d'un point et dans le noeud de NOE produit du déplacement effréné d'un point, on relève dans les éléments de la séquence EBN une complexification dégressive du mouvement, du moins en termes d'éléments de géométrie linéaire.

EBN, par découpe, par pli et par nœud, détermine des interventions dans l'indéterminé de l'uniforme du monde. Croissance de densité dans la progression des procédés puisqu'il n'y a pas de tranches dans la continuité, ni entrelacs dans la matière, ni marques dans l'indistinct. Établir point, ligne, surface comme dénominateurs géométriques de ces objets construits tout en privilégiant les opérateurs découpe - pli - noeud comme fonctions topologiques dans le sens précis de propriétés invariantes au-delà des déformations géométriques et concourant à signaler un même processus de transformation continue.

EDN, un lieu se découpe dans un lieu; BLL un objet se plie dans un lieu; NOE un objet se noue entre deux lieux... Trois logiques comme trois formes de raisonnement stratifiés sur les frontières. Départageant l'inclus de l'exclu, EDN impose le seuil, point d'entrée ou de non-retour. Sa réitération dans BLL devient fil conducteur tressant le processus tandis qu'en NOE, la frontière bifurque et s'abîme dans l'énigme et le paradoxe. 
EBN rupture la chirurgie plastique de l'objet: en EDN les contours limites fluctuent, en BLL sa progression est complète même si elle se présente inachevée et en NOÉ voguant sous des cieux troublés, la constellation de ses éléments qui la constituent, s'échangent leur jeu de rôle.

EDN privilégie l'écart, BLL privilégie la limite et NOÉ l'incertitude entre l'écart et la limite. Toutefois, dans les effets phénoménaux de cette séquence, le chaos, les fractales, les catastrophes des figures relèvent d'un même niveau de complexité.

\section{EBN: UN RÉCIT POLICÉ D'OBJETS FRACASSÉS}

Le récit nous méduse. Confortablement assis sur le "banc de quêteux" de nos habitudes ou mis "au pied du mur", la texture devient le lieu privilégié de la répétition, de la copie. C'est l'effet de surface que l'on retient. Pour si peu, dire qu'on glisse par la texture dans la surface des choses. Réversibilité dynamique, en s'y infiltrant sans limite, la couleur les maquille: polychromies, glaçures, faux-finis. Jusqu'aux limites de l'effritement de la masse dans la lumière. Le miroitement lumineux substitue sa fragilité à la masse de l'objet. Glace-miroir, texture mouroir de l'objet, NOE "sans ciel ni terre"... (modernité lisse et anti-polychrome...).

L'apport d'échelle dans la maquette et de répétition dans le modèle introduit un virtuel, l'objet étant "à la fois là et ici, mais ni ici ni là tout à fait". L'échelle "cathénarise" les objets, les réunit. Exprimer la singularité par le rapport d'échelle, analogue mais non identique, l'objet n'étant ni fracassé ni fragmenté mais chaotique et fractal.

Le récit nous méduse par la peau lisse de son image: en deçà l'ossature dynamique des objets s'installe et au delà, la perception de "l'édénisation", de la "babélisation", de la "noétisation" comme processus continus et intégratifs de l'hominisation s'affirment.

Nos objets découpent, plient et nouent leur silhouette dans l'ombre portée de ces "grands récits".

En tant que sculpteur, témoigner d'une sensibilité aiguë à l'espace et ce qui en modifie les rapports: latitude de l'expérience concrète, platitude du récit ressassé... 


\section{EBN: UN REGISTRE DYNAMIQUE}

Lapidaire comme EDN, impliqué comme BLL, lisse et obscur comme NOE, l'objet EBN ainsi se donne.

EBN est un registre de trois dynamiques, chaosmose expose l'amplification de celle-ci. EBN est une remontée à la source de toute légitimation, elle dit rapport à la loi, l'autorité, à la capitale et majuscule du Livre.(Byblos)

Retourner aux origines, c'est prendre et comprendre large. C'est aussi en revenir et prendre le large. Non pas tant prendre voie ou voix d'autorité que s'ancrer dans le réservoir d'une tradition généreuse à saveur de bouillon amniotique.

Là où EBN se donne comme texte, chaosmose se crie tel un slogan.

De même que les organes du corps n'existent que reliés même s'ils se donnent à voir dans l'analyse comme séparés, tenter de poser EBN comme structure phénoménale. Ainsi comprise, l'analyse des parties de la proposition n'a d'autre fonction que de faire connaître les éléments et surtout les effets de mise en relation réciproque.

EBN n'appartient pas au registre des tératologies hybrides. Inoculé contre le syndrome Frankenstein, il n'a que faire du rapiécage de morceaux qui flottent aux courants de l'histoire de l'art. Lorsqu'il commémore par l'usage du monumental, un collectif généreux alimente sa dynamique.

Et c'est pourquoi, bien au delà des cliniques d'esthétisme épidermiques, mise en forme de la surface, le rapport EBN propose la "permanente", une "mise en pli" devenues le lieu chaosmatique et festif de trois régimes de dynamiques qui s'y compactent et concassent et compressent. Bien sûr, ça grince... L'image nous entraîne, nous enchaîne.

EBN, trois récits mythiques, trois singuliers "cas de figure", une même construction de la réalité. Et sans hybridation parce que de même nature. En tant que rapport, ce produit nous mène en avant. 


\section{EBN: UN ESPACE INAUGURAL DU CONSTRUCTIVISME}

Dispositif en réseau, tel un filet lancé pour disposer du sens. Ici s'annonce l'horizon du processus.

Quelle est sa singularité, son ton local? Dans l'instant l'objet méduse, tétanise, lobotomise. Il stupéfie, crispe et se "livre sans histoire". Ce que contrecarre la publicisation du processus à l'occasion d'un symposium par exemple.

Imposer à la "non-nécessité" moderniste de l'art une relation de nécessité dans le tressage EBN. Établir les surfaces de coïncidences: trois constructions s'y délivrent.

Le récit d'EBN rend visible le processus de construction, l'objet ainsi produit le rassemble. Ainsi compris, il inaugure dans la réalité de la longue chaîne des objets fabriqués qui le suivront un caractère fondamental de radicalité. "Au début était...".

Dans l'origine de ces aménagements paysagers, de ces tours d'habitation, de ces engins à voyager prend position le transport EBN en tant que singularité exemplaire et irréductible d'un objet que véhicule et reconstruit comme ici et maintenant le langage. L'agglomération des termes EBN tresse une opacité. Se posant en énigme à la connaissance, elle indispose.

Le projet de construction oriente le destin, la destinée, la destination de l'objet. Ainsi le récit d'EBN tout à la fois inaugural, radical et fatal peut-il se contrer.

Là où le livre installe par ses trois récits d'Eden, de Babel et de Noé radicalement, c'est-à-dire aux origines, une fatalité, -puisqu'il s'agit de trois aventures fâcheuses-, la construction définie comme projet oriente le destin de l'objet. Construire, c'est changer et les choses et l'ordre des choses. À terme, dans la chaîne du récit, la séquence des objets se dresse CONTRE LA FATALITÉ. C'est ainsi qu'à EBN qui se pose en énigme, l'objet construit par la fête des mains manifeste en ses plis l'explication amplifiée.

Comme un ver solitaire, c'est la fatalité qui s'y replie. 


\section{EBN: UN COLLECTIF CONTRE LA FATALITÉ}

Ainsi donc, dans le texte inaugural, une fatalité radicale mais dans l'émergence de l'objet survient le front du refus. EBN perpendiculaire aux érosions évasives du rituel.

$\mathrm{Au}$ début était EDN in-situ de la maison commune et c'est bien après que nous naissons à notre raison de l'habiter. Littéralité de l'allitération, la conscience et son expression par le langage, là-bas par le serpent, ici aussi sinsinue et suit l'installation dans la réalité. Elle bafouille à sautemouton d'entre ces trois objets radicaux, dérive et délire dès qu'elle s'autonomise en langage. Théoria/Théorie, procession/spéculation: le bla bla bla du discours-tambour ferme la parade fluide des objets.

Au passé d'EDN, paradis du chantier de la nature domestiquée, les couples de la terre se forment par attribution. Aux couples de forces de BLL qui bâtissent par attraction, l'espace manifeste de la plate-forme spatiale. À Noé l'instant qui manipule le mouvement par attrition: un territoire du passé, un monument futur et le présent humain en résistance, "n'y voit ni ciel ni terre". La forme épique de l'intégration serait-elle dans le consensus compressé?

EBN instrument du collectif, du communautaire. C'est en EBN que le mot accompagne la forme, celle du collectif et du compagnonnage. En termes de thématique, EDN dé-s'installe le couple, BLL les tribus humaines et NOE les espèces animales... EBN donc "sème à tout vent".

La dynamique EBN devient génératrice d'espaces typifiés. Espace familier du vernaculaire, EBN a "les pieds sur terre". Souligner la fécondité de cet espace radical parce qu'aux origines, là où prennent racine l'individu et son collectif.

Le livre d'Autorité, le Grand Récit est déchiré et c'est tant mieux, c'est dans nos récits quotidiens que se tisse notre dignité. Ici plus qu'ailleurs, l'Humain fait l'Homme. Dans ce sentiment du collectif qui nous relie (religere-religion).

\section{Refus d'oublier et la fête, et les exclus de cette fête.}

EDN un lieu; BLL un processus; NOE une quête/une enquête. La science actuelle produit de l'inconnu, tout comme l'objet sculpture. 


\section{EBN: UNE STRUCTURE VERNACULAIRE}

S'agissant de trouver des surfaces de lieux communs aux trois figures, ainsi pourrait-on dire qu'EBN s'inscrit dans l'espace vernaculaire, dans celui de "l'entrepreneurship" ingénieux, à proximité du bricoleur et du patenteux. Là où NOE "nous mène en bateau". Voilà le caractère commun de leur espace singulier. Le développement, le déroulement de l'espace de ce lieu révèle tout un plan d'action. C'est le caractère propre de chaque objet sculpture d'en signaler l'instant privilégié.

Autant EDN, BLL, NOE pris séparément se présentent comme des espaces, des architectures, des gîtes singuliers que nous pouvons habiter, puisque nous pouvons en être exclus, d'autant chaos, fractales et catastrophes deviennent les sites privilégiés d'effets dynamiques qui bouleversent, fragilisent et compressent la séquence des objets.

Dédoublement éthique du langage, comme une réalité à deux vitesses que signale ainsi l'écart entre le sédentaire institué, professionnel passionné et constructeur de style en vis-à-vis du nomade amateur, dilettante bricolant l'ornement. Au bricolage primaire se valide la construction universitaire! Le patenteux "chef d'oeuvreux" ingénieusement réconcilie cet écart dans l'espace vernaculaire de la nécessité quotidienne: "le premier étage de l'ascenseur de Maslow, tout le monde descend!"

Et si privilégier la construction au 20 e siècle participait d'un même esprit, de la même fonction symbolique que la prédilection du $19 \mathrm{e}$ siècle pour la composition et de certains peintres des $17 \mathrm{e}$ et $18 \mathrm{e}$ pour la géométrie...Pourquoi pas? EBN posé en énigme à comprendre pour en prendre large..."prendre le large"! Cette figure du constructeur se substitue à celle du Créateur et privilégie l'espace de survie à l'espace sidéral, l'installation verbeuse parfois, au Verbe institué (installer: arranger, disposer, mettre, placer; instituer: commencer, créer, fonder, instaurer).

Séquences rythmées d'objets solides, reliés aux origines et travaillant en interface (EDN), en réseaux (BLL), en noyaux (NOE), toutes ces formes s'installant dans un sol de gravité, sol gravide s'il en est puisque c'est là que le matériau technique et le matériau social plongent dans les plis de la nappe sémantique, là où le sens fait poids: site, abri, gîte. 


\section{EBN/UN DRÔLE DE RÔLE POUR UN CONSTRUCTEUR}

EBN témoigne de l'arbitraire de son phantasme millénariste.

Estella, astella. Sous le chapiteau des étoiles, copeaux d'atelier du monde, voilà le lieu privilégié où EBN forge ses désirs: parcours de recherche de la filiation du sens des mots... Solidement installé organiquement au coeur de ce qu'il travaille, bien aux écarts de la blanche aseptie d'une salle d'opération muséale, affirmant son rejet de l'actuel virtuel ("probabilité du probable").

Partie liée à la survie, travail d'un collectif, et accessible à tous, c'est dans ces lieux ouverts, dans l'espace du public qu'il pose ses installations, formes mémoires collectives. Et l'objet alors, comme lieu de convergence d'une pulsion et d'un code, signale la concrétion de ce lieu d'expérience soumis à une audience, à une publicisation.

Le symposium comme pratique locale en extension du tribal et qui se voudrait intégrative de l'Internationale. Un profil particulier de l'ouvrier se dessine, celui qui répondant au cas par cas travaille à s'installer avec clarté dans un lieu tandis que l'objet, la sculpture, répondant à l'énigme de l'aventure au minimum charrie l'opacité du problématique.

C'est là le caractère propre de sa singularité locale. Mais qui a dit qu'il appartenait à ces travailleurs de combler un vide idéologique ou de prolonger une religion tombée en déshérence?

La preuve que l'art s'est substitué à la religion est phénoménologique: ce sont des créateurs non pas des artistes, créant des créations non pas produisant des objets. M'apprenant ce que je ne savais pas, dieux s'ennuyant dans leur solitude, ils se cherchent toujours en recherche. À trois milliards à se parler, ça fait du monde... Travailler à construire des modèles d'échange, une table où le monde s'asseoit. Sans "souffle" divin, ni "inspiration". Contre-pied de la fatalité: mort d'un système de rédemption. À l'urgence cristique de se sauver répond maintenant l'invitation à naviguer...

Absence de statues pose la question du statut et du salut! La fonction générative d'EBN privilégie le site, le gîte, le bâti. Elle profile la figure de l'architecte, du bâtisseur qui commande, de l'ouvrier qui ordonne. 
Là où EDEN se conquiert par la durée linéaire et où BLL se juge dans le feuilleté de ses horizons statigraphiés, NOE débarque dans l'incertitude de l'instant indéterminé et non linéaire.

Dans les strates du langage, se dressent fièrement les figures emblématiques de l'architecte constructeur savant, de l'ingénieur responsable d'ouvrages de génie. Le parler populaire auréole l'ingénieux touche-à-tout d'un brouillard "de patentes-à-gosses" à saveur de catastrophe... Au spectateur en déroute de la perspective classique en point de fuite, EBN rassemble par compagnonnage,par perspective axonométrique et propose le stage de la corvée et la convergence de l'art populaire (perspective classique; grille moderniste; hologramme post-moderne). Hologramme, rassemblement par résolution de l'image.

\section{EBN: TERMINUSVILLE}

EBN véhicules, EBN gîtes... Rappel de certaines évidences, celles des conditions initiales: à l'origine un discours, le discours à l'origine et un discours d'origines... Dans ce discours, trois figures et entre celles-ci une séquence imposée. Oscillation éthique d'Eden, prolifération virale de Babel, accumulation du capital de Noé. Se retrouvent curieusement en EBN les phantasmes hantés de cette fin de siècle post-moderne! Sans masse, sans volume...

Récit balbutié aux origines, EBN nous accompagne et s'accroît à la dimension de notre compréhension actuelle de ces choses. Nous circulons vers son développement ultime. Si EBN n'est que ruines derrière nous, c'est bien droit devant nous qu'il érige déjà la plénitude de sa survenance.

Au générique de "l'atelier du monde en travail", EDN BLL NOÉ deviennent acteurs performants, opérateurs génératifs. Le réseau des formes, la solidarité des supports, le bonheur de certaines rencontres, voilà la thématique. Travail de résistance à l'effondrement du sens produit par la poussée expansive de chaosmose.

Aux trois registres de dynamiques d'EBN, la table d'écoute de chaosmose s'expose comme le lieu d'inscription amplifié de cette complexité: EDEN ANTIQUA, BABEL FUTURA, NOE AVENTURA. 


\section{CHAOSMOSE: CONSTRUIRE DU RÉEL}

Conquête de la surface d'un territoire, même pas d'une ligne de crête mais d'un point d'où pourra décliner son identité la chaîne continue d'un processus de production de sculpture. La figure du géographe se substitue à celle du géomètre et s'impose comme archétype du constructeur. Et celle du constructeur s'impose comme prototype de la fonction d'artiste.

Chaosmose - Le noeud du noeud bâtit un édifice, abri d'une unité structurale: chaosmose gîte au site central de cette unité.

Comment nommer en effet ce mouvement de balottage tantôt apaisant, ramenant du sens et nous consolidant à l'intérieur? Affirmant des acquis par des apports inédits, il produit une sorte de brassage positif, de compactage. De l'autre, euphorie, émerveillement, nouveauté, éclatement! Remise en question positive du connu, effrittement par grignotage de l'expérience nouvelle, sorte de concassage de ce que l'on tient en nous pour solide.

Chaotique certes, mais tout ça avec une périodicité ample, quasi cosmique et qui, euphorie passée, laisse plénitude et s'osmose à nous. Chaosmose. Émotion résumant, modélisant le mouvement incessant de compactage/concassage de l'expérience et du changement.

Phase du pli, du dépli, du repli de la dynamique des rapports par le tressage, le tissage, le repassage; là où tel un slogan et cri du coeur chaosmose se donne comme contexte. EBN dynamique, chaosmose thématique!

Partager en aussi agréable compagnie que James Joyce, Edgar Morin, Félix Guattari ou Kenneth White cette émotion ne la rend peut-être pas moins bizarre mais décidément plus confortable.

Chaosmose, mot qui n'a pas froid aux yeux. Mot qui s'explose, qui s'installe exposant de puissance. Voilà la source d'énergie qui travaille le matériau de base EBN.

Chaosmose mot-valise, commis-voyageur virulent. D'entrée de jeu il cogne, met K.O. : "K.O.smose...". Visuellement, l'acronyme surligne la violence. Le K, consonne (K-sonne) occlusive sourde, fait trembler. Bruit sourd d'un tremblement de chaos. (K.O. Et si l'on risquait d'y perdre "la peau et les os?") Et rien de tel pour sonner la charge que de frapper à coups 
redoublés: !"..os...os". La puissance de la figure d'allitération fait écho, "en remet!" Osmose où l'agglutination des sens accompagne l'itération formelle ("Pogné en dedans? Marche dehors!)".

Mot oxymore qui en un premier temps veut rompre, mettre K.O. pour se finir rassembleur dans l'étreinte de l'osmose, figure de l'interpénétration en douceur de deux termes. L'oxymore fonctionnant ici en écran de projection, non pas opaque mais transparent. On y lit "entre les lignes" tout le cosmos s'y profile, rien de moins! Figure de compression, effet de dilatation, mot qui littéralement en met "plein la vue": mot-valise pour objet-balise.

Exposant chaosmose il ne s'agit plus là d'un événement local mais d'un phénomène généralisé, d'un état qui occupe toute la surface. Ce cosmos défini comme tout l'univers présenté sous forme de système ordonné devient la figure porteuse et emblématique du mouvement dense des objets. Un espace totalement ouvert à l'humain, cosmos coïncide avec l'atelier du monde.

Et l'osmose comme tentative de "combler un manque à gagner" entre notre compréhension et notre émotion devant la réalité. La procédure tente de sauter la faille par le biais de matériaux construits. Chaque tentative d'y jeter un pont en ajoutant d'une part à la chaîne des choses, par effet analogue au paradigme holographique, puisqu'on "fait toujours la même sculpture" augmente la définition de l'image. Paradoxalement la signification ne suit pas, elle fuit!

Cette fuite, pour chaotique qu'elle soit, explicite le processus dynamique de la démarche. $\mathrm{Ce}$ qui cherche à s'énoncer ici est que le sens entendu comme signification y perd au profit du sens comme direction. Il y a là un processus d'osmose.

Au plan des sens, de l'émotion, l'objet mis sous tension au seuil de l'éclatement pourrait communiquer sensiblement la cohésion tandis que l'oeil agité en perçoit le tourbillon... Plaidoyer ahurissant pour l'art comme expression de la beauté.

D'une beauté qui s'accorde à des exigences de révolte, qui trouve dans la crise comme objet la dynamique et la volonté de construire des objets en crise et qui appartiennent en partie à cette beauté explosante fixe des surréalistes, lieu concentré d'échanges, de péripéties et de plaisir. 
Et c'est ce chaosmose qui permet dans une équation formaliste construite, à fonction programmatique, de faire un lien organique avec les données théoriques du surréalisme. Le surréalisme comme la rencontre fortuite (chaosmatique) sur une table de dissection (un lieu) d'un parapluie (un objet) et d'une machine à coudre (un processus). Méthode d'itinérance des sens par proximité, allitération, jeux de mots. Ses mots d'ordre: poésie, amour et révolution. Régime ternaire ici aussi.

La première information que doit livrer le sculpteur est son adresse soit, à la fois la localisation de son espace concret et son procédé de découpe, comme pierre, dressée... Le premier message du sculpteur est son adresse: "D'où es-tu?" Le premier sens de la sculpture est de s'ériger contre la fatalité de la chute. Pourquoi craindre qu'elle se réduise à la seule signification de sa singularité entendu que c'est toujours le tissu social qu'elle hante, "Patente Géniale?"Osmose, quand la forme raisonne par résonance.

D'EDN, BLL, NOE comme strates différenciées d'un vecteur en progression constante de complexité, pour mettre en branle un processus auto-organisationnel de rétroaction positive à l'effet boule de neige issue du Big Bang: de l'espace institutionnel vers le terrain résidentiel. En réalité, dans les marges chaotiques du chemin public et de la propriété privée, dans cette frange d'interférence où cabanes d'oiseaux et maisons d'enfants se disputent en discontinuité avec la "fardoche" et où en équilibre non linéaire la statuaire des calvaires prend le relais des déchets. Cueillette sélective, déplacement obligé dans la chaîne des représentations de la métaphore onctueuse vers l'âpreté métonymique, sa littéralité, là où également l'accent du travail est porté davantage sur la régie organisationnelle que sur les catégories stylistiques du jugement esthétique. Monumentalité motive, vocation donc que tenterait de réaliser en territoire de ruralité la "Patente Géniale".

Histoire d'un homme marchant entre Eden Babel Noé et Chaosmose les deux pieds dans l'atelier du monde. Heureusement tout le monde n'est pas obligé de remonter au Déluge pour faire de la sculpture! 


\section{CHAOMOSE}

ATELIER DU MONDE EN TRAVAIL implique EDN, BLL, NOE Chicoutimi 1999 


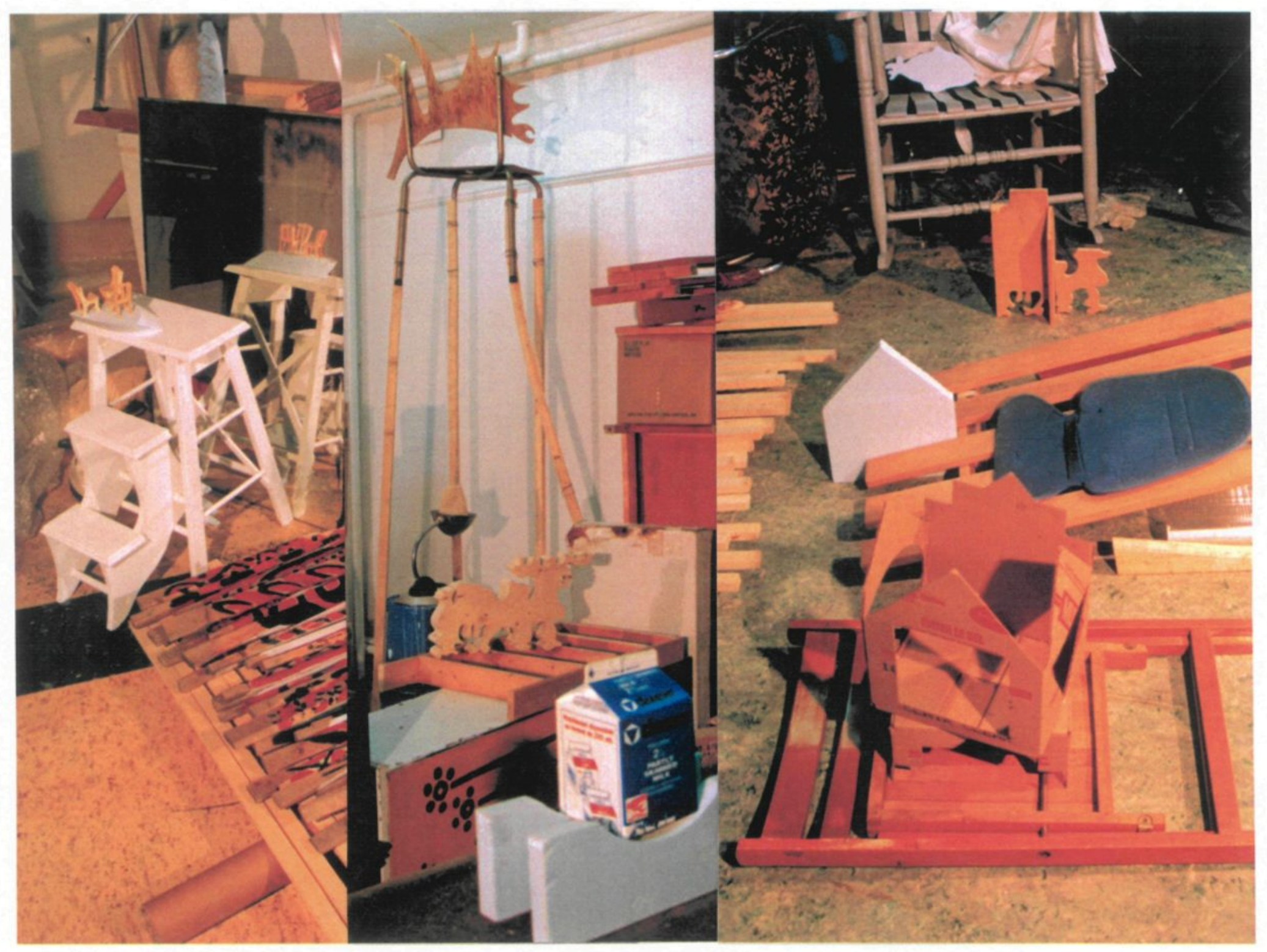




\section{BIBLIOGRAPHIE}

Deleuze, Gilles : $\quad$ Rhizome : introduction, Gilles Deleuze, Félix Guattari. Paris: Éditions de Minuit 1976.

Morin, Edgar : $\quad$ L'Unité de l'homme : essais et discussions présentés et commentés par Massino Piatelli-Palmarini.

Paris : Éditions du Seuil 1978.

Morin, Edgar: $\quad$ La méthode : T.1. La nature. T.2. La vie de la vie. T.3. La connaissance de la connaissance. T.4. Les idées leur habitat, leur vie, leur organisation. .

Paris : Editions du Seuil 1977.

Morin, Edgar: $\quad$ Le paradigme perdu : la nature humaine.

Paris : Éditions du Seuil 1973.

Thom, René : $\quad$ La magie contemporaine : l'échec du savoir moderne, sous la irection de Yvon Johannisse avec la précieuse collaboration de Gilles Boulet .

Paris : Flammarion 1994.

Thom, René : $\quad$ Paraboles et catastrophes sur les mathématiques, la science et la philosophie, réalisés par Giulio Giorello et Simona Morini. Paris : Flammarion 1983.

Watzlawick, Paul : $\quad$ L'Invention de la réalité : comment savons-nous ce nous croyons savoir? : contributions au constructivisme, traduit de l'allemand par Anne-Lise Hacker.

Paris : Éditions du Seuil 1988.

Watzlawick, Paul : La réalité de la réalité : confusion, désinformation, communication, traduit de l'américain par Edgar Roskis. Paris : Éditions du Seuil 1978. 
Watzlawick, Paul : Changements : paradoxes et psychothérapie, traduit de l'anglais par Pierre Furlan.

Paris : Éditions du Seuil 1975.

White, Kenneth : $\quad$ La route bleue, traduit de l'anglais par Marie-Claude White.

Paris : B. Grasset 1983.

White, Kenneth : $\quad$ La figure du dehors.

Paris : B. Grasset 1982.

White, Kenneth : $\quad$ Approches du monde blanc suivi de Le territoire de l'être, traduit de l'anglais par Michelle Tran Van Khai et Marie-Claude White. Paris : Nouveau Commmerce 1976. 